\title{
Pre-Service Physical Education Teachers' Discourses on Learning How to Become a Teacher: [Re]Constructing a Professional Identity Based on Visual Evidence
}

\author{
Mariana A. da Cunha ${ }^{*}$, Paula Batista and Amândio Graça
}

CIFI $^{2}$ D, Pedagogy of Sport, Faculty of Sport, University of Porto, Porto, 4200-450, Portugal

\begin{abstract}
Identity has been used as an analytical tool to capture how teachers work, learn and develop professionally. This paper takes chiefly Gee's [1] discursive notion of identity to examine the discourses that pre-service physical education teachers used about themselves and others in discussing their teaching practices in the context of their practicum training in school. More specifically, this study aims to identify and characterize the situations of concern [roles, individuals, groups, events, meanings] to the pre-service teachers when learning to be a physical education teacher and when [re]constructing their professional identity through a dialogic relation between talk and images. Nine preservice teachers from the Faculty of Sport, University of Porto participated in this study. Data were gathered using photo elicitation interview technique: photographs and videos, produced by the participants, were used as prompts for discussion in two focus group sessions [2,3]. We adopted an inductive approach to thematic analysis based on the Grounded Theory coding principles $[4,5]$, supplemented by a situational analysis [6] to map visual discourses and construct photo-essays [7] upon them. The images portrayed the participants in situations of classroom practice, learning-to-teach resources, social recognition and teachers' mission. Their discourses upon those photographs and videos recognized the physical education teacher as a type of teacher who: [i] cares for planning duties, carefully prepares their lesson and complies with institutional roles, as planning and teaching; [ii] constantly searches for professional excellence and updates their knowledge [e.g. transferring pedagogical strategies fromother contexts]; [iii] individually/collectively reflects upon their practice, learns and shares knowledge with their colleagues, is in constant development, and builds their identity in allegiance with others [e.g. class observations and mentoring meetings]; and [iv] extends their school practice beyond the instruction tasks and has the power to project and exercise higher roles [e.g. extracurricular roles].
\end{abstract}

Keywords: Discursive identity, physical education, teacher education learning, visual methods.

\section{INTRODUCTION}

The student teaching practicum is considered by the research literature on teacher education as the most significant component of a teacher training programme [8]. It is in this stage of initial trainingthat students make the transition to certified teachers and begin to internalize a much more genuine and stronger sense of teacher identity which will support and sustain their future progression as education professionals $[9,10]$. Specifically, during preservice training, students develop a set of attributes they need for a deeper understanding of the complexities of practice and of ethical conduct associated with the work by teachers [11]. Shulman and Shulman [12] grouped the attributes of accomplished teachers into six clusters, which refer to cognitive, dispositional, motivational, performance, reflective, and communal dimensions. The body of literature also points to the ability of the pre-service teachers to cope with their school teacher educators' philosophies on teaching

*Address correspondence to this author at the $\mathrm{CIFI}^{2} \mathrm{D}$, Pedagogy of Sport, Faculty of Sport, University of Porto, Porto, 4200-450, Portugal;

Tel: +351 22.04.25.284 / +351 91.890.19.22;

E-mail: marianacunha@fade.up.pt and prevailing practices in different practicum settings, while struggling to fit in on an ideal concept of professional teacher [13]. Learning to teach is, therefore, a social process [14]. The notion of "being a teacher" is socially legitimized through the teachers' interactions with other members of the profession, parents and children [15]. As such, the process of "becoming a teacher" involves much more than acquiring a new set of knowledge and skills [16]. In this regard,Britzman [14] states that "learning to teach is not a mere matter of applying decontextualized skills or mirroring predetermined images; it is a time when one's past, present, and future are set in dynamic tension" [p. 8]. The author underlines, in particular, that "learning to teach - like teaching itself - is always the process of becoming: a time of formation and transformation, of scrutiny into what one is doing, and who one can [or aspire] to become" [p. 8]. For this reason, Luehmann [16] remarks that this transformative process could be better understood and supported through the theoretical lenses of identity development.

Recent literature on teacher education highlights the importance of using identity development as an analytic framework to better address aspects of teaching and, most specifically, the challenges of becoming a teacher [17-20]. 
Concerning identity development, over the last twenty years, the focus has been ongradually replacing more traditional views of how teachers develop, which were predominantly based on the acquisition of assets, such as knowledge, competences and beliefs $[17,21]$. Similarly, the prevailing ideathat there might be one [self], predetermined, fixed or given, sustained and unchanged identity [22-24] is, nowadays, fading away. Alternatively, a social constructivist paradigm is gaining ground while arguing that identity can never be something that is just internal as it is necessarily relational, and has to do with the recognition of sameness and difference between ourselves and others [24].

Within this general framework, identity has been defined through a number of diverse lenses. Owens, Robinson and Smith-Lovin [25], for example, identify three distinct intellectual traditions in research on identity: personal identity, situated identity, and collective identity ${ }^{1}$; whereas other authors focus on the sources of identity, including the self [26, 27], emotions [28, 29], communities of practice [30, 31], social and contextual factors [32], levels of change [21], teachers roles and practices [33, 34], stories and narratives $[35,36]$, among others. Nonetheless, despite of the complexity of resolving it into a unique definition, teacher identity is generally conceived as a constructed, fluid, dynamic, ongoing, recursive, impermanent, multifarious, multiple, fragmentary, transient and sociallyconstituted process of interpretation and re-interpretation of experiences, situated in circumstances and settings that both impact and are impacted by the teacher $[18,20,22,37,38]$. In a dialogical approach, both unitary and multiple; continuous and discontinuous; individual and social; person and context; personal and professional aspects of a teacher's professional development should be considered [17, 37]. In other words, personal history, social interactions and psychological and cultural factors influence the identity construction [39].

In this respect, Gee [1] defines teacher professional identity in terms of the processes of recognition occurring in the interpretations of common everyday experiences. Most specifically, this author uses the term identity to mean "being recognized by self or others as a certain kind of person in a given time and context" [p. 99]. In this sense, all teachers have "multiple identities" [1], or "sub-identities" [37], which are connected more significantly to their performances in society than to their "internal states". This is not to deny that each individual has what one might call a "core identity" that holds more uniformly, for oneself and others, across contexts. In addition, Gee [1] sketches out ways of recognizing a person as "a certain kind of person[teacher]" in four perspectives: nature [stemming from one's natural state], institutional [derived from a position recognized by authority in society], discursive [reflecting on how a person is ascribed by self and others] and affinity [determined by experiences shared with other people].

The research literature has been specially emphasizing the role that talk and discourse play in teacher identity construction [1, 40-43] drawing, predominantly, on interpretative small-scale and in-depth methods of research,

1Personal identity refers to the individual's internalization of social positions and their meanings within a self-structure; Situated identity is shaped through consensual and cultural meanings elicited by social contexts; Collective identity places the concept of the identity at the group level. [25]. such as individual semi-structured interviews and focus groups [23, 44-46]. For example, Brown and collaborators [44], Cohen [45], and Day and collaborators [47] stress the intricate connection between identity, language and teaching/classroom learning, while arguing that teachers' talk of their experiences both in school and in student teaching practicum settings are essential to our understanding on how they construct and re-construct their professional identities. Therefore, "language in this context entails more than understanding the thematic patterns, semantic relationships, and syntactic forms of [teachers'] discourses"[p. 781], [44]; rather, employing a particular discourse allows an individual to become recognized as a certain kind of person within a certain context [1].

Thereby, the literature keeps reiterating the need for further elaboration of the concept of identity in distinct empirical fields, using a varied range of methods to enhance new understandings on teacher professional identity [17]. As such, the research question that provides the focus of this study is: How Portuguese pre-service physical education [PE] teachers [re]construct their professional identities through talking about themselves and others in relation to their teaching practices during the practicum training?In particular, this paper explores the pre-service teachers' discourses on their daily practices in school in the context of their student teaching practicum training.

In order to answer to the research question, the theoretical framework used was Gee's definition of identity [1] - i.e. "being recognized as a certain kind of teacher". Taking as its central theme his discursive notion of identity, and using visual evidence such as photographs and videos as stimuli $[2,3,7,48]$, we examined the discourses that preservice PE teachers used about themselves and others in discussing their everyday-lived experiences in school: teacher learning and development, professional roles, responsibilities and teaching practices.

In terms of structure, we start out the paper by exploring the selected concepts and findings from research on identity development as it applies to this study - i.e. discursive notion of identity presented by Gee [1]. We will then progressively incorporate subsidiary elements to identity, such as the notions of "agency" and "structure" [49, 50], "legitimizing identity", "resistance identity" and "project identity" [51] to shed light on how pre-service teachers learn to become PE teachers. Finally, we address the empirical research developments using discursive identity theory.

\section{THEORETICAL BACKGROUND: LOOKING FOR A CONCEPTUALIZATION OF TEACHER IDENTITY}

«Identity is manifested through social interaction, [...] including those processes created through language» [Brown, et al. 2010, p. 783].

The concept of "identity" is central to many studies in contemporary society, including the field of teacher development. Identity has currently been seen as something constructed, fluid, multiple, impermanent and fragmentary [22]. Moreover, the construct of 'identity' has been explored, contextualized and deployed in a variety of ways, such as 
through the notion of discourse [see, for example [44, 45, 1, $20,16,23]$, and [46]].

\subsection{The Discursive Construction of Teacher Identity}

Cohen [45] highlights the need to account for teachers' professional identity: "accounting for teachers' representations of their experiences through talk, is essential to our understanding of their professional identity" [p. 473]. Specifically, teachers' talk about their professional experiences, and subconsciously of their identities, is central to the beliefs, values, and practices that guide their engagement, commitment, and actions in and out of the classroom [47, 52]. Similarly, Beijaard and collaborators [53] emphasize that "teachers' perceptions of their own professional identity, [manifested through speech], affect their efficacy and professional development as well as their ability and willingness to cope with educational change and to implement innovation in their own teaching practice" [p. 750]. In this context, Danielewicz [42] specifies that "identities are produced through participation in discourse", which is manifested through language, and "consists of a system of beliefs, attitudes and values that exist within particular social and cultural practices" [p. 11]. Brown and collaborators [44] also define discourse or languageas "a communicative situation", "an interaction", "an exchange" [written, read, spoken or enacted], "an active resource", "a practice" through which speakers and listeners co-construct, negotiate and interpret meaning that serve to position them[selves and others] as particular types of people [pp. 781-783]. It is within this understanding that Gee [1] presents his theoretical model for identity development.

Gee [1] regards "identity" as a socio-cultural construct forged in terms of the processes of recognition occurring in the interpretations of common everyday interactional experiences. This author describes, in particular, identity as the "kind of person one is recognized as being, at a given time and place" [p. 99]. Specifically, when a person interacts with others, he or she engages in what Gee [1] calls identity "recognition work" by using language and "other stuff ways of acting, interacting, feeling, believing, valuing, together with other people to recognize [ourselves] and others as meaning and meaningful in certain ways"' [p. 20]. The same author argues that recognition work is something "we all do all the time" [p. 14], as people "try to make visible to others [and to themselves, as well] who they are and what they are doing" [p. 20].

At the heart of this definition lies the need for individuals to understand the interpretative processes that serve as the subtext of identity [54]. Furthermore, it is through the social process of recognition that social groups, such as teachers, get established and maintained. The validity of a particular group then depends very much on its members recognizing each other's ways of talking, thinking, and interacting as appropriate to the group [45]. Thus, it is embedded in the earlier statements the notion of identity as a dynamic entity that "can change from moment to moment in the interaction, can change from context to context, and of course, can be ambiguous or unstable" [p. 99], [1]. Following the author's definition of identity, "discourses are ways of being certain kinds of people" [p. 110]. Notwithstanding, the identity possibilities accomplished through discourse are constrained, among other aspects, by normative beliefs and practices, as well as material conditions [45]. For this reason, Gee [1] proposes different circumstances that determine 'who' an individual is seen as being, by providing a total of four distinctive identity perspectives: nature, institutional, discursive and affinity.

The first perspective, "nature" or "N-Identity", is "a state developed from forces in nature" [p. 100], [1], and refers to conditions over which an individual has no control. In this way, one's identity is determined by the natural characteristics that come to define an individual. The source of this power is nature, not society, for example, race, gender, being a twin.

In the second domain for identity analysis, the "institutional-characteristic" [I-Identity], one's identity is affirmed or determined through institutional means. In other words, identity is defined in terms of the positions of an individual that are sanctioned by authorities within an institution. The position of a pre-service teacher or a teacher in general is an example of this kind of I-identity. As such, the source of power resides in a set of authorities, and laws, rules, traditions and principles drive the process of authorization. In this context, Castells [51] refers to a "legitimizing identity" supported by systems of domination composed of the market and its legitimizing institutions, such as schools and colleges. In this "institutional or legitimizing perspective", one is expected to perform particular roles consistent with the norms conveyed by the social structure or system one pertains to. The notion of "structure" entails, therefore, the rules and resources enforced by social systems which seem to influence, constraint or limit the choices and opportunities that individuals possess [49]. According to Giddens [50], this concept inherently extends to the notion of social positions and relations an individual develops amongst social positions. In the opposite side of the spectrum lays the notion of "agency", considered by Beauchamp and Thomas [18], and Beijaard and collaborators [37] as an important element in defining teacher identity. Teachers, as individuals, are social actors; they do not limit their action in integrating the school community and in fulfilling their roles as teachers. They also transform the daily school life through their practices. This means that teachers have to be active in the process of professional development. Respecting this, MacPhail and Tannehill [49] define "agency" as the capacity of the individuals to act independently and to make their own free choices. Castells' reinforces this point of view by presenting the concepts of "resistance identity" - reflecting individual or collective struggles to surpass the domination of the systems - and "project identity" - involving the construction of new identities that imply the transformation of the overall social structure [51]. The notion of "resistance" encloses the need to struggle for one's point of view and values, as opposed to simply endure what is institutionalized. However, in addition to "resistance", is important to incorporate aspects of transformation, innovation, change and dissemination of new modes of conceiving and performing the teaching-learning process. 
Regarding this, Giddens [50] adds that "agency concerns events of which an individual could, at any phase in a given sequence of conduct, have acted differently. Whatever happened would not have happened if that individual had not intervened" [p. 9]. In this statement, notions such as "free will" or "volition", "empowerment", "individuality" and the capacity to "act" or "doing" are strongly connected, echoing in the teaching profession or other social occupation, a dialectic relationship between both views - structure and agency/ legitimizing and resistance. As such, project is sought since social structures influence human behaviour, but humans are also capable of changing the social structures they inhabit $[49,55]$. The following two domains of identity of Gee's framework [1] reflect more closely these ideas of "agency", "resistance", "project" and "collectivity".

The third marker of identity sketched out by Gee [1] is the "discursive perspective" or "D-Identity", which draws special attention to the relationship between the discourses that are used to define people, i.e. it is concerned with the significance of how people talk about others. Under the presented conditions, Gee's D-Identity defines ways that descriptors and labels are produced to provide identities. The sources of this view are "rational individuals" [p. 103], [1] who "treat, talk about" one and another through the interaction amongst themselves; and the power is the talk, discourse or dialogue itself. In this regard, "Discourses" are defined as "ways of combining and integrating language, actions, interactions, meanings, ways of thinking, believing, valuing, and using various symbols, tools and objects to enact a particular social recognizable identity" [p. 21], [1]. Cohen [45] finds it helpful to "apply the notion of identity recognition by thinking of talk as a series of identity bids that depend on recognition from others to be successful"'[p. 475]. The author grounds teachers' talk as an understanding of discourse as a semiotic tool for constructing the significances of specific social roles an individual can occupy. In this sense, Gee [1] argues that it is only because other people talk about and treat an individual in a certain way that he or she becomes that person. By extension, the discourses used to both describe oneself and groups of people such as, for instance, "pre-service teachers", will determine the way in which they are perceived. To be clear, it is through the interpretations of one's participation within these professional "Discourses" that a professional identity develops. As such, as Luehmann [20] enlightens, "the participation in the professional Discourses is required, but it is the interpretation or recognition of that participation, by self or others, that identities are formed" [p. 827]. Brown and collaborators [44], on the other hand, refer to "discursive identity as involving how language is used to accomplish a symbolic identity through signalling membership into particular groups" [p. 787]. Thus, for example, one's identity as a "pre-service teacher" type of person is ascribed by the use of the term "pre-service" as a means to define or describe the individual. This is a reflexive process, as the individual must engage in activities that define them as "pre-service teachers" and others must interpret this behaviour similarly by using the term "pre-service" as an appropriate descriptor. As such, language and messages have the power to contribute to how one's identity is constructed and to indicate group affiliation and membership [56].
Gee's fourth and final notion of "affinity-identity" [AIdentity] defines identity in terms of the experiences shared or participated in the practice [power] by "affinity groups" [source] [1]. This perspective indicates, therefore, membership into a domain of identity based on a shared set of cultural and behavioural practices. To constitute an affinity group, individuals must share "allegiance to, access to, and participation in specific practices that provide each of the group's members the requisite experience" [p. 105], [1]. In this way, one's affinity to engage in common activities leads to the appropriation of the identity that is common to the shared practices.

Summing-up Gee's [1] conceptualization of identity, the "Nature-identity" refers to a process of state designated by natural forces; the "Institution-identity" denotes a position held in an organization; the "Discourse-identity", an individual trait attributed by others, and we would say further, by self; and finally, the "Affinity-identity", alludes to experiences and practices shared by members of a community. According to this viewpoint, all of four identity strands coexist in the identity of an individual, and obtain meaning through social interaction in institutions, discourse, or affinity groups as people recognize and categorize each other [1].

\subsection{Discursive Identity as a Lens for Physical Education Teacher Learning}

Our study is underpinned in the theoretical background that takes on "identity" as a socio-cultural construct following Gee's conceptual approach to identity, applied to mean the "ways of being 'certain kinds of people' " [p. 110], [1], or, more specifically, "certain kinds of teachers" [20, 23] that emerge with respect to the discursive notion of identity i.e. from how they are talked about and from the recognition of particular traits by self and others. This view considers, therefore, teacher development and identity construction as a dynamic, ongoing and social process of interpretation and reinterpretation of experiences situated in circumstances and settings that both impact and are impacted by the teacher [20, $37,38]$.

In this context, identity may be understood primarily in terms of the discursive perspective, although specific links to institutional and affinity perspectives [1] cannot be ignored.

As McDougall [23] points out, the discourses under scrutiny are not just those used to describe specific individuals, but those that apply to pre-service Physical Education teachers as a group and the responsibilities of teachers as a collective. Consequently, institutional views are also relevant in this context, since the ways in which the preservice PE teachers talk about their practices and responsibilities might be influenced by the ways in which the "values, attitudes, and viewpoints of institutions [...] have floated into people's everyday recognition systems" [p. 104, 1]. The institutions that might inform the position of the preservice PE teacher are not just governing bodies and policymakers, materialized in the norms of the Teaching Programme of the Faculty, but the broader community, including the teacher educators [faculty-based tutor and school-based mentor], school more experienced teachers, 
students, parents and, in particular, general pedagogical and ideological guidelines. Therefore, the source of "power" that might determine the role of the pre-service teacher is a complex set of authorities, professing an equally complex range of ideologies to which teachers are expected to cope with [23]. Moreover, the pre-service PE teachers' conceptions of identity will also be influenced by "affinity groups" [p. 105] [1], i.e. with whom they identify with. In particular, their professional identity is developed through the interactions established with the members of the professional learning community [30] they belong to, and their sense of identity will be either validated or challenged according to these allegiances. Pre-service teachers who share similar pedagogical approaches amongst themselves and other teaching colleagues are more likely to reinforce particular teaching identities [23].

As such, the construct of identity employed in this paper acknowledges that the discourses teachers use in describing their teaching learning, development and role may be influenced by their understandings of institutional expectations, as well as the ways in which they identify with others. Specifically, pre-service PE teachers and teachers in general have their own ideas of what defines their professional identity and are capable of exercising their own "agency" through discourse or actions. However, it is likely that these views will be influenced by the roles imposed on them by various institutional bodies [e.g. faculty and school], as well as by those affirmed by other teachers with whom they share similar beliefs and practices - i.e. the faculty and school "structure" [23]. In other words, while pre-service teachers may have some freedom to exercise their own will to act in a school, their actions are likely to be constrained by the accepted and conventional practices of teaching. In addition, pressures from the PE teacher education programme syllabus, more experienced teachers, school principals, and even peers may prevent pre-service teachers from having a free reign in doing anything they want [49]. Nonetheless, the concept of "agency" besides enabling us to examine what the pre-service teachers 'do' in their school contexts, also may provide the basis to explore the social positions and relations between social positions that arise as pre-service PE teachers undertake teaching duties in school [49].

Therefore, the identity discourses of pre-service PE teachers may be influenced by the standpoint of all those who author their position, their affinity to particular individuals or groups of individuals, as well as their power of exercising their own ideas and ways of teaching in school.

\subsection{Empirical Developments on Discursive Teacher Identity}

The outlined theoretical framework on identity in particular, the discursive way of conceptualizing this concept is consistent with the principles of symbolic interactionism in the epistemological tradition $[57,58]$. This perspective denotes that our notion of self emerges through an appreciation of how others see us. In this respect, symbolic interactionists argue that interaction takes place in such a way that the individual is continually interpreting the symbolic meaning of his or her environment [which includes the actions of others] and acts on the basis of this imputed meaning [59]. Furthermore, the arguments presented by Gee [1] demonstrate significant theoretical resources for reconstructing the notion of identity within the educational research [44].

Research on teacher education has identified ways discourse mediates teachers' voices on educational reforms and teacher preparation programmes, as well as teachers' thoughts about teaching and learning. For example, McDougall [23] showed how discourse served as a resource for primary teachers to talk about their reactions to teaching media. Cohen [45] demonstrated how professional identity can be negotiated through talk by middle and high school Humanities teachers [an interdisciplinary programme combining English and Social studies], as a means to pattern knowledge and behaviour, in order to get recognized as a certain type of person. Trent [46] used the discursive construction of teacher identity to give voice to the criticisms of pre-service English language teachers on their teacher education programmes. Luehmann [20] employed discursive identity theory to analyse science teacher preparation programmes and to address the challenges of becoming a reform-minded science teacher. All of these pieces of research were drawn on small-scale studies using preferentially semi-structured interviews and focus groups.

Although studies in teacher education have been employing the discursive notion of identity, little attention has been given to the field of PE teacher education, and in particular, to the way the discourses of pre-service $\mathrm{PE}$ teachers contribute to the construction and re-construction of their situated views of identity. Given the examples provided above, the discourse of teaching-learning experiences can provide useful insights about how pre-service teachers learn to become PE teachers during their practicum training and, consequently, a way to use discourse to symbolically cue their identity. More specifically, this consideration of identity can offer arenovated lens for viewing student teachers in discourse events.

Lastly, research literature on identity theory points to the need of employing distinct and innovative research methods in order to go beyond the limits of language and capture the meaning of lived experience in a more holistic way [60,61].

In this chapter we drew from a theoretically relevant model of identity development, such as the incorporation of the notion of discursive identity as an analytic tool [1], to set the stage for our study and further discussion regarding the ways pre-service PE teachers develop, shape, construct, and co-construct their own, as well as those of others, identities during the student teaching practicum training.

\section{THE STUDY}

\subsection{Research Design}

This paper aims to examine how pre-service PE teachers' constructed their professional identity during the practicum training throughout discourses about their lived experiences. 
Table 1. Demographic Information on the Pre-Service PE Teachers and their Practicum Context.

\begin{tabular}{|c|c|c|c|c|}
\hline \multicolumn{5}{|c|}{ City Centre School } \\
\hline Nuno & Male & 23 years-old & $11^{\text {th }}$ grade & $2 \times 90^{\prime}$ \\
\hline Patrícia & Female & 25 years-old & $11^{\text {th }}$ grade & $2 \times 90^{\prime}$ \\
\hline Name & Gender & Age & Grade Level & Weekly Classes \\
\hline João & Male & 23 years-old & $11^{\text {th }}$ grade & $3 \times 45^{\prime}$ \\
\hline Bárbara & Female & 23 years-old & $11^{\text {th }}$ grade & $3 \times 45^{\prime}$ \\
\hline \multicolumn{5}{|c|}{ Suburban Coast School } \\
\hline Name & Gender & Age & Grade Level & Weekly Classes \\
\hline Francisco & Male & 26 years-old & $12^{\text {th }}$ grade & $2 \times 90^{\prime}$ \\
\hline Vanessa & Female & 22 years-old & $12^{\text {th }}$ grade & $2 \times 90^{\prime}$ \\
\hline Inês & Female & 23 years-old & $12^{\text {th }}$ grade & $2 \times 90^{\prime}$ \\
\hline
\end{tabular}

* The attributed names are fictitious.

To this end, we adopted a photo elicitation, qualitative methodology [2, 3, 7]. This research method consists of introducing photographs and films into the interview context such as focus groups, produced, in this case, by the participants [62].

The photo elicitation technique is an approach to visual methods, described as any research design which uses visual evidence, for example camera and photographic images [63]. According to Harper [3] and Phoenix [48] images offer a different way to access information. Namely, photographs and videos [i] evoke deeper elements of the human consciousness, such as feelings, memories and emotions on the participants' lives; [ii] prompt discussions about a phenomenon; and [iii] gather complexly-layered meanings than words alone do, in a format which is both accessible and easily retrievable to researchers, participants and audiences alike.

The visual methods can therefore represent a distinct way of exploring the pre-service PE teachers' discourses about their daily experiences. These include teaching practices, roles and responsibilities, in a situated context [the practicum training], as well as the modes in which they [re]configured their professional identities in the process.

\subsection{Participants and the Context}

The participants were nine pre-service PE teachers selected from a cohort of students attending the final year of the Master's of Teaching programme of a Portuguese Faculty of Sport, according to the following criteria: [i] all students completed their Sports Sciences undergraduate degree in the same faculty where they were taking their Master's; [ii] a site supervisor expertly tutored the participants; and [iii] the pre-service teachers were mentored in school by cooperating teachers with over ten years of experience of pedagogical supervision. Four of them were male and five were female, and their ages ranged from 22 to 26. The research took place in the 2010-2011 academic year during the second semester of the participants' practicum training. Each participant was allocated to one of three secondary schools, three cooperating teachers and three groups of practicum, that were supervised by the same faculty supervisor. One school was urban, located in the city centre of Porto; the other two were suburban, one located inland and the other situated in the coast. The urban school had older facilities and more limited conditions for the practice of PE, whereas the two suburban schools were completely renewed, presenting modern and higher quality levels in terms of spaces and equipment to teach PE classes. All pre-service teachers taught the final years of the secondary level of education, i.e. the $11^{\text {th }}$ and the $12^{\text {th }}$ grades, for a full academic year [see Table 1]. They spent four days a week in school carrying out teaching activities [e.g. classroom planning, instruction and evaluation] and participating in the school and local community activities [e.g. supporting the form tutors duties and the school sports practices, collaborating and creating extracurricular activities]. Their practice was monitored daily by their cooperating teacher through individual and collective meetings. In particular, there was a collective seminar with the group of three pre-service teachers, and three individual seminars with each student; both types of meetings had a length of 45 to 90 minutes dedicated to the agenda of reflecting upon the observed lessons and other activities developed during the week. Lastly, the supervisor visited their schools three times during the year, one in each term, to both observe their lessons and assess how they were 
experiencing their learning and professional development. Overall, these meetings concurred to the main goal of enhancing their professional competencies and identity construction during the process of learning in a real teaching context.

\subsection{Data Collection}

A combination of visual data and focus groups was used for data collection. Specifically, data were gathered through photo elicitation during two focus groups sessions. The visual methods technique outlined was employed to answer two purposes: enhance an understanding on the pre-service teachers' daily teaching practices and encourage the participants to openly share their feelings and thoughts within a group of pre-service teachers $[2,3,7,48]$. On the other hand, the focus group was employed 'to build up a view out of the interaction that took place within the group' [p. 473], [59]. The corpus of the research was, therefore, the two recorded focus group sessions and the respective set of images.

To this effect, the participants were asked in advance to take their own photographs and videos during a period of one to two weeks. The pre-service teachers used their own digital cameras, selected the photographs and videos, and organized them into Power Point presentations to be used later on at the focus group sessions as discussion stimuli. Specifically, the set of images [photographs and videos] were exhibited and described by each participant and jointly discussed by the group of nine pre-service teachers in the focus groups.

The first focus group was held in February and participants presented and discussed images related to the school experiences considered as the most relevant to them, with respect to the teaching and learning organization, the participation in school and relations with the local community, and their professional development. This session lasted 77 minutes. The second focus group occurred in May and the participants talked about the nature of their daily practices in school via the displayed images, namely: tasks imposed by the practicum training programme, duties performed by self-initiative, tasks they felt interest in, and those leading to challenges and anxiety. The second focus group session lasted 100 minutes.

The two focus groups were audio-taped and the discussions were transcribed verbatim.

\subsection{Data Analysis}

In the process of analysis, we used an inductive approach. Substantive themes were defined as they emerged from the data according to the overall principles to coding of 'grounded theory' [4, 5] [open, axial and selective procedures], supplemented by a cartographic situational approach to analysis [6]. This involved a thematic analysis of the photo elicitation interview data using QSR NVivo 9.0. Specifically, we took five main steps: [i] Each transcription and image was read, interpreted and analysed separately to break down data into themes and to start laying out an initial map on the major situational elements within data [individuals, groups, events, sites, ideas, concerns and meanings] addressed to each image and narrative discourse; [ii] Subsequent readings were conducted to search for recurring themes and regularities, as well as contrasting patterns in each pre-service teacher's accounts and across pre-service teachers' discourses on the exhibited images, in a systematic and interactive way. This process involved revising, collapsing and expanding, adding and deleting the categories in the map using the method of constant comparison to imprint some order to the messy situational maps initially constructed; [iii] We then took a relational analysis was then undertaken to specify the nature of each element or category on the map through the procedure of questioning data and memoing the answers; [iv] At some point, we reached saturation and thematic discourses, constructed and agreed upon with the images, started to emerge, supplemented by direct quotes from the participants. The purpose was to illustrate and situate the themes, as well as to glean meaning out of the visual and discursive data; [v] The final outcome was a photo-essay $[3,7]$ consisted of thick descriptions relating the knowledge represented in the images and the discourse generated around them, both by those in it, i.e. the participants, and the researcher.

Four main identity discursive themes emerged from data: [i] Classroom practice; [ii] Learning-to-teach resources; [iii] Social recognition; and a sense of a teacher's Mission. These main themes were broken down in the sub themes presented in Table 2.

\subsection{Ethical Considerations}

This study was approved by the Ethical Committee of the Faculty of Sport, University of Porto [Process CEFADE 09/2012]. Despite the impossibility to guarantee anonymity and confidentiality resulting from the use of images, an informed consent, asking permission to publicly use the audio and visual material in academic contexts, was obtained with the participants before the focus group sessions. Notwithstanding, pseudonyms were appointed to each preservice teacher in all the material, transcripts and analysis, and any personal tracking details removed. Furthermore, the identity of people, other than the research participants, captured in the images used in this study, was protected through the usage of digital image editing tools.

\section{RESULTS}

The key emergent identity discursive themes applied to the day-to-day teaching practices in school, shared by the participants were those of classroom practice, learning-toteach resources, social recognition, and teacher's mission. Within each core discursive theme, particular sub themes emerged as the most stressed by the group of pre-service PE teachers and are addressed in detail. The selected photographs and quotes represent the collective views of all participants.

\subsection{Classroom Practice}

In the participants' discourses, actual teaching was the most valued role amongst the experiences of being a preservice PE teacher in school, as reflected on Bárbara's words: 
Table 2. The Pre-Service PE Teachers' Discursive Themes and Subthemes in learning to be a teacher.

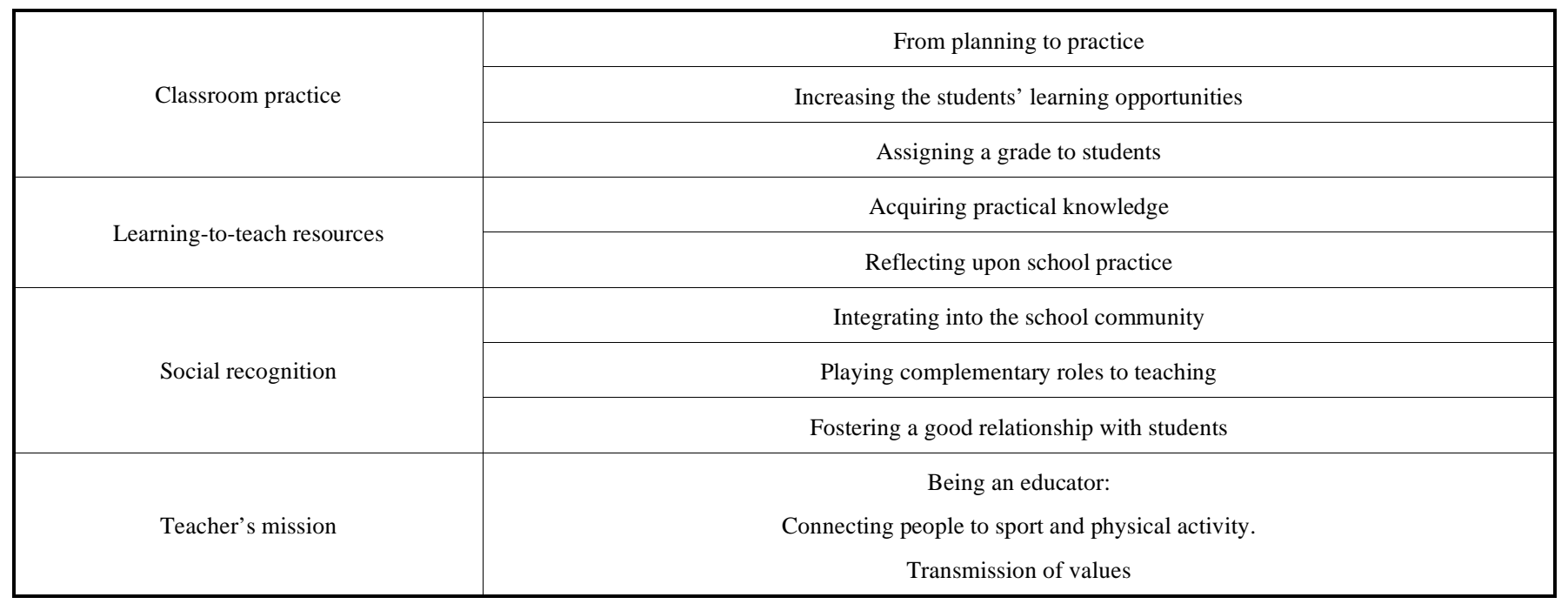

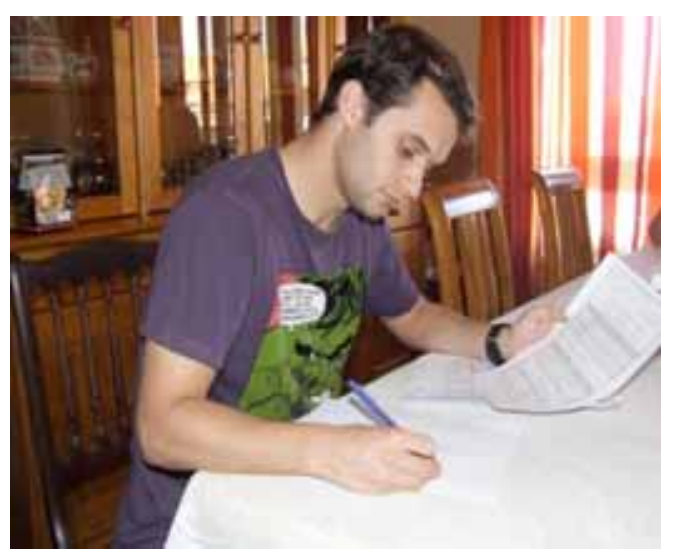

Fig. (1). Reviewing the lesson plan before going to action.

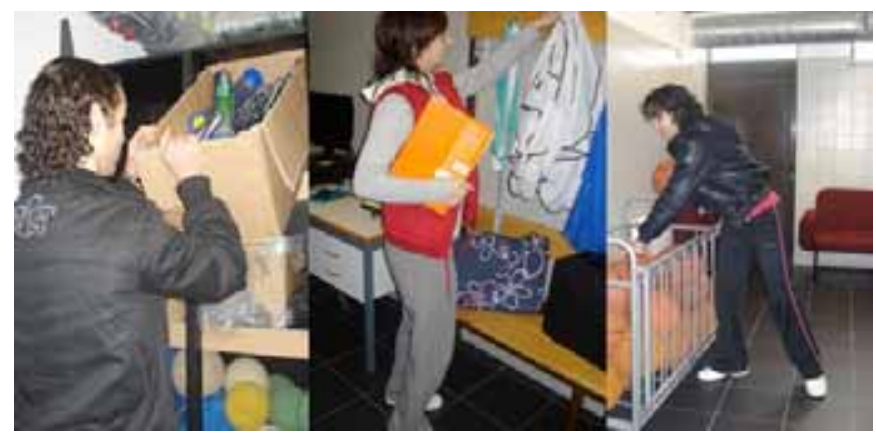

Fig. (2). Collecting the PE equipment - A transitional moment.

It is in the act of teaching that we feel well. It's what completes us as teachers [Bárbara].

Their accounts on teaching-related experiences featured situations of planning, instruction and evaluation.

\subsubsection{From Planning to Practice}

In (Fig. 1) Nuno is reviewing his Badminton lesson plan at home. In particular, he planned his lesson based on the Sport Educational Model [SEM] instructional guidelines, as forming heterogeneous groups in class and assigning specific roles to the students [e.g. coaches, team captains, referees].
Nuno presumes this image to be representative of all the work behind the act of teaching, such as:

Choosing the learning situations, establishing groups, thinking on the tasks transitions, assigning roles to the students, and counting the tournament points of the previous lesson...Thinking about all the organizational aspects, so that everything goes well in the field [Nuno].

Another task preceding instruction highlighted by the participants was the equipment preparation. In (Fig. 2), Francisco [left], Vanessa [centre] and Inês [right] are picking up the PE equipment they need in the immediate moments 


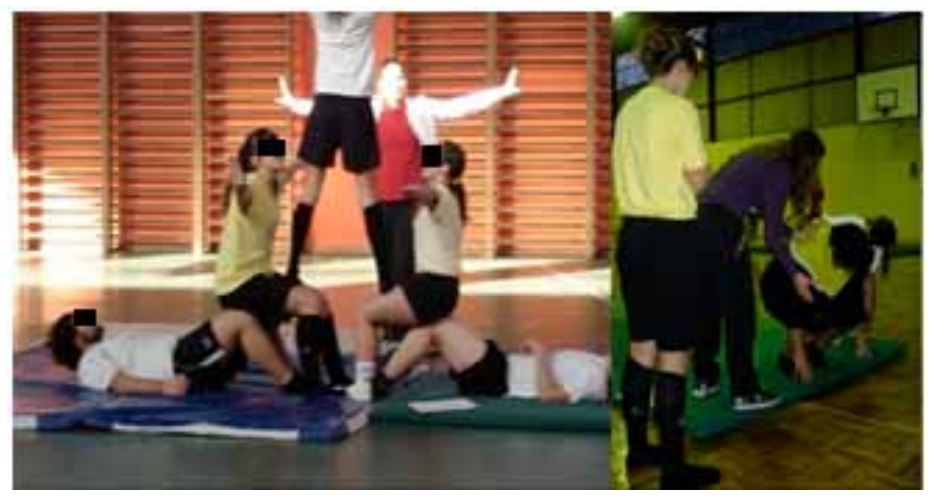

Fig. (3). Employing the Sport Educational Instructional model.

before starting, respectively, their badminton, football and basketball classes.

They represent the interface from planning to practice, as Francisco notes below:

It is Thursday morning and I am in the storing room gathering the equipment for a Badminton class. This image depicts the transitional moment from the planning process to action, in which the teacher puts into practice what he had planned for his or her students [Francisco].

This process involves the mobilization of an evolving knowledge based on previous training, experiences and reflective exercises about their own school practice. Vanessa corroborates this idea while highlighting the importance of preparing instruction in accordance with the contextual characteristics one teaches in:

[...] it corresponds to the moment before putting to action our knowledge, experiences, reflection and volition in order to comply with the class' needs, curriculum goals and school context [Vanessa].

Inês, in contrast, highlights the issue of the school's equipment resources and emphasizes the constraints that she felt while planning and preparing her Basketball lesson:

The real issue here was the fact that we did not have basketball backboards in this school. How can I plan and teach a 90-minute basketball class without backboards and baskets? I had to unleash my imagination and creative side in order to plan motivating basketball lessons for my students [Inês].

In this respect, Francisco reinforced his colleague's point of view by discussing the value of the school equipment resources:

[...] for us teachers to meet the PE programme goals [Francisco].

Bárbara, however, shared a different point of view:

More than being dissatisfied with the available resources, shouldn't we be endlessly dissatisfied with our performance? Do we actually potentiate the means that we have at our hands? Hmm... [Bárbara].

With this statement, Bárbara tried to convey that a good teacher must always positively embrace the challenges presented to him or her. A teacher should be enthusiastic and passionate about the profession. This is significant because a teacher contributes to the overall education of an individual and, ultimately, to the transformation of society. For this reason,

[...] one should not get carried away by the difficulties that are presented to one self in a particular point in time. A teacher should gather all efforts and means to overcome the barriers [Bárbara].

\subsubsection{Increasing the Students' Learning Opportunities}

Fig. (3) depicts Bárbara at the school's Gym in two of her Acrobatic Gymnastics lessons where the students were working in groups and accordingly with the SEM orientations. All class worked in a third of the total space of the Gym delimited by curtains and each group worked on a set of three to four matresses.

The pre-service teacher stressed that the purpose of applying this instruction model in particular was to enhance her students' development of their aesthetic perception, cooperative behaviour, creativity and, more broadly, to promote the gyminastics sport unit practice in her class. Specifically, Bárbara [left] is placed at the centre of the acrobatic position and facing the female student on the top,

[...] showing how she and her classmates should straighten their arms in order to best fit with the sport acrobatics formal features [Bárbara].

In addition, Bárbara and a female student [right] are helping an over weight male student with his backward roll. His group had decided to include this pre-acrobatic element in their collective routine and his peer playing the coach role insisted that he would perform it.

Suddenly, all the team was around him and committed to helping and encouraging him with the backward roll and... he ended up to actually doing it! [Bárbara].

As such, Fig. (3) and the related discursive markers presented above, intend to underline the power of the SEM in developing motor skills, cooperative and inclusive attitudes, self and group achievements, feelings of festivity, as well as a commitment towards the PE subject matter in the students.

The participants also reported other teaching strategies to further commit their students to the PE subject matter, 


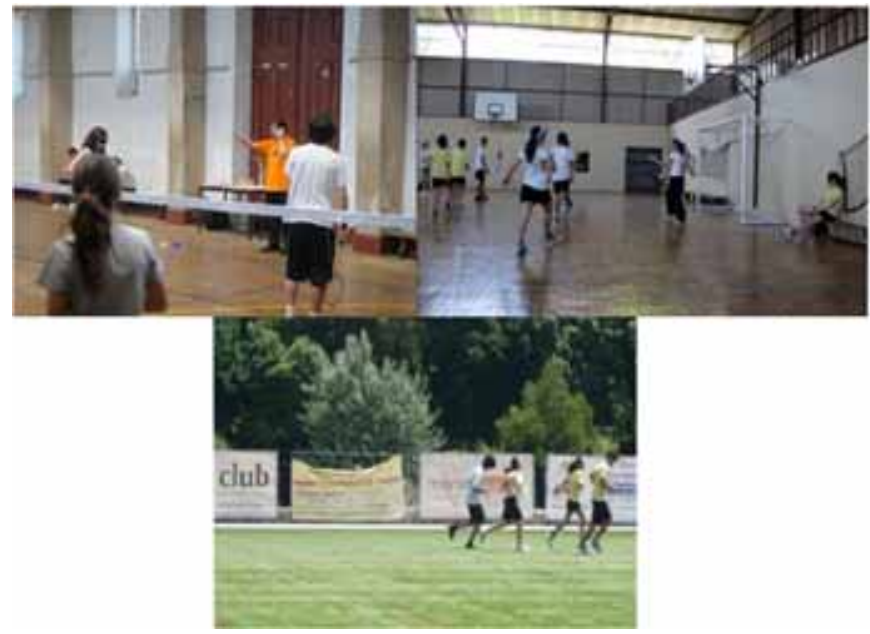

Fig. (4). Teaching optional sport units: Badminton, Dance and Orienting.

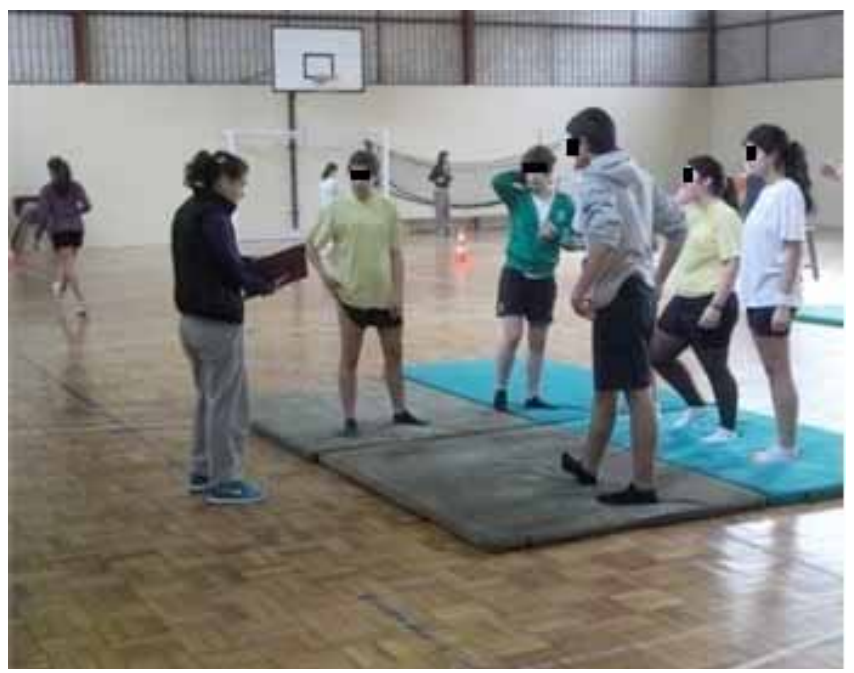

Fig. (5). Assessing students learning using the IPP.

enhance their motivation and good behavior in class, and increase their learning opportunities, such as: teaching optional sport units [badminton - top-left, dance - top-right, and orienting - centre-bottom] and wearing attractive ornaments as Elsa's hair ribbon portrayed in the top-right photograph in Fig. (4):

The ribbons were essential elements to personify the rock ' $n$ roll era and to fully engage my students in the dance sport unit [Elsa].

Elsa also implemented the routine of conducting the warm-up and cool down exercises with music to, on the one hand, systematically improve her students' notion of rhythm since they were due to present a dance routine at the end of the year; and, on the other hand, to encourage proximity, not only amongst the students, but also between the students and the teacher,

\section{[...] so that an effective learning may occur [Elsa].}

\subsubsection{Assigning a Grade to Students}

In (Fig. 5) Elsa is holding a clipboard and updating the Individual Plans of Progress [IPP] with each student of a working group.
The pre-service teachers devised this pedagogical tool to daily assess, control, supervise and enhance their students' self-commitment to their own skill achievements. In this regard, Elsa explained the foundations of this evaluation instrument:

After the 1st term final evaluations and the initial assessment made on the sport units to be taught, at the beginning of the 2nd term, we created a document for each student with their individual goals for the term in the following three dimension: 'knowing', 'knowing how to do' and 'knowing how to be' in a PE class [Elsa].

Each student would be responsible for the achievement [or not] of their own goals; scheduling and registering them in their personal IPP columns:

[...] aspects to maintain; aspects to improve; and general comments [Elsa].

In each class Elsa would monitor all groups and students to update her own file, which is precisely what she is doing in Fig. (5). Despite the initial doubts on whether this strategy would work or not, Elsa was happy with her class accomplishments: 


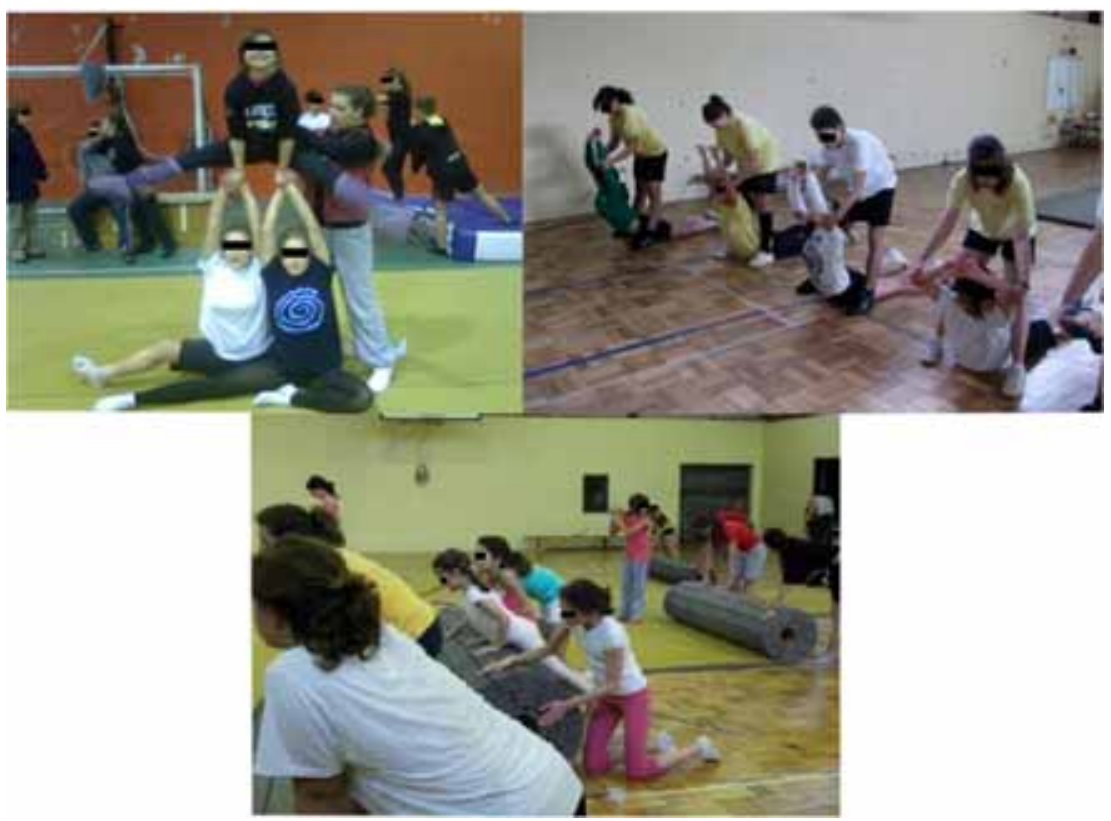

Fig. (6). Contributions of the school sport practice to the PE class.

This is actually working very well. They are extremely motivated. Most of them are meeting their goals ahead of time. Moreover, they are always reminding me: 'Teacher, tomorrow do not forget that I have that goal to work on'! [Elsa].

Evaluation is a sensitive teaching-learning topic to the pre-service teachers, on which they aimed to improve during their practicum training. They revealed feeling recurrently anxious when it came to perform this institutional task:

I always wondered whether I was being fair in assigning a particular grade to a student.I always felt anxious at the end of a sport unit. [Nuno]

The IPP is an example of a pedagogical strategy devised by some of the pre-service teachers, to overcome the difficulties addressed to the issue of evaluation while fostering autonomy, sense or responsibility and learning progress in their students.

The images presented so far instigated, therefore, the participants to talk about a legitimized practice within the teacher profession and teaching training, which is planning classroom instruction and teaching.

In this respect, the initial pair of photographs recognized the PE teacher as someone that cares for planning duties and carefully prepares his or her lessons. Moreover, a teacher should be a resistant and projective person to surpass the institutional difficulties presented to him or her. Therefore, in the context of classroom instruction, the use of different teaching models, as the SEM, and teaching optional sports in the PE classes seemed to be the discursive bids more valued in the pre-service teachers' talk about their teaching practice. They considered them as instructional strategies to increase the learning opportunities of their students. The implementation of the SEM also represents a renewed way of perceiving the teacher-student relationship in a classroom. The participants see the student as a subject of his or her own learning process. As such, through last three images the participants described a PE teacher as someone who constantly searches for effective instructional strategies to be implemented in his or her class in order to increase the learning opportunities of their students.

\subsection{Learning-to-teach Resources}

The pre-service teachers highlighted a variety of learning situations during the focus interviews. These were related to their daily practice in school which helped them in the preparation of their PE lessons and classroom performance, as well as in their professional development. Specifically, mastering practical knowledge in school sports practice and with expert teachers, and reflecting upon practice during school and training meetings, class observations, and writing-up activities. The quotes below are examples of these concerns:

In order to feel more motivated in teaching and to develop ourselves professionally, we must have an in-depth knowledge of the subject matter. [Francisco]

Working and reflecting together enables us to [...] improve and adjust our teaching plans and practices to the characteristics of our class, the sport unit content we're teaching and the school's agenda, in general. [Vanessa].

\subsubsection{Acquiring Practical Knowledge}

The photograph on the top-left of (Fig. 6) portrays Elsa [behind the trio group] helping a young female student performing the angle position on the top of two female bases at the Gym in the school sport acrobatic weekly practice. The picture on the top-right portrays a warm-up exercise to train the flexibility of the back muscles at the beginning of one of Elsa's PE class. In the photograph on the bottom, all children are gathering-up the sport acrobatics practice equipment, such as the mattresses. 


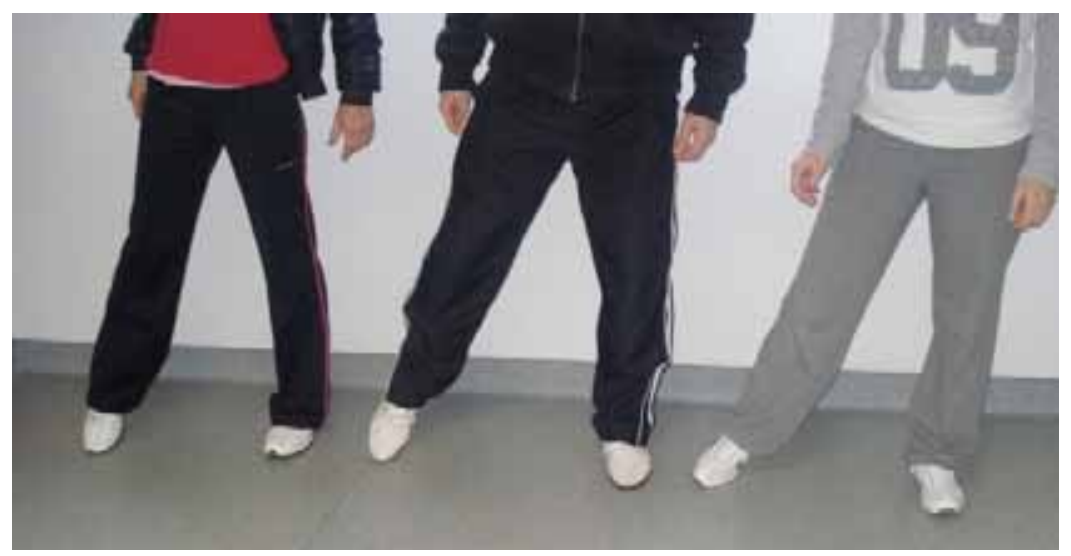

Fig. (7). Learning a Cha-cha-cha step with an expert teacher.

Sport Acrobatics is one of the chief sports extracurricular activities offered by the school where Elsa and Bárbara took their practicum. Since the beginning of the year Elsa and Bárbara had actively accompanied the Sport Acrobatics practices three times per week [Wednesdays, Fridays and Saturdays], as assistant teachers. According to both, this role improved considerably their teaching skills and enhanced their feelings of affiliation to the Sport Acrobatic Club. In particular, the top-left image in (Fig. 6) was taken to share the pedagogical strategy usually used in Sport Acrobatics practice in the pre-service teachers' school, 'working through achievements', as Elsa explains below:

They must achieve a minimum of ten successful repetitions on each performance series of an acrobatic element. As you can see, the student on the top is still very young. She's in the primary school next to our secondary school, and she's having difficulty in raising her legs to execute the angle. So I'm helping her. However, from the fifth/sixth repetition or when the position is simpler, I encourage her to do it by herself. [Elsa].

The picture on the top-right is another example of a strategy taken from the Sports School practice that can be used in a regular PE class in a warm-up exercise characteristic of the Gymnastics sport unit in general. Likewise, Elsa and Bárbara also implemented the workout and management routines learned in the Sport Acrobatics Club, at the beginning and end of their Gymnastic sport unit in PE [centre-bottom image]. Ultimately, these photographs aim to convey the transfer of knowledge and experiences, acquired as assistant teachers at the School Sport Acrobatics Club, to the PE Class's planning and teaching, as quoted below:

Many of the exercises that I do in my PE class, namely, the warm-up at the beginning of a Gymnastics lesson, come from my experience in the School Sport Acrobatics Club. So, what I see and learn from what they do in their practice and consider as an interesting situation that can foster a fruitful learning, I try to apply it in my PE. [Elsa].

The selected images also imply that each sport has its own unique aspects, thus a teacher's teaching practice should reflect them. According to Elsa's views, a teacher should aim to master the content matter of their subject:
Each sport has specific aspects. Therefore, our actions should be differentiated depending on the sport we are teaching. No doubt that in general a Gymnastics lesson's warm up exercises should be longer and more incisive in certain domains such as joints, flexibility and so on, than in other sport units. [Elsa]

Fig. (7) gives another example of the pre-service teachers search for practical knowledge to surpass their personal limitations and enhance their teaching competences. In this photograph the pre-service teachers Inês [left] and Vanessa [right] are learning a Cha-cha-cha step from an expert teacher [centre], specialized in Ballroom Dancing.

They were urged to learn that Cuban dance because, at the beginning of the academic year, the PE teachers group of their school decided that all PE teachers should teach Chacha-cha in their classes. The pre-service teachers did not master this particular activity unit, because during their undergraduate degree and teacher education training they had only a very brief contact with Ballroom Dancing.

Alluding to the limitations of their experience as students at university, Francisco reported the stressful incident of a student passing out in his class and the anxiety he felt while dealing with the situation:

We're not prepared to deal with this kind of stuff. We did not have a first aid course in faculty. I had to stop all class and call for an ambulance. We did not resume the lesson that day [Francisco].

Similarly, teaching particular activity units in school such as dancing, orienting, swimming, badminton and sport acrobatics posed significant difficulties to the pre-service teachers mostly due to their unfamiliarity with the subject. Hence, they revealed how they overcame the dance unit challenge:

We have been having lessons with a teacher who previously was a Ballroom Dancing national champion and now provides training. There is nothing better than that to learn the Cha-cha-cha basic steps and overcome the gaps of our academic training! [Francisco].

Vanessa emphasizes not only the value of learning from a colleague specialized in Ballroom Dancing, but also its 


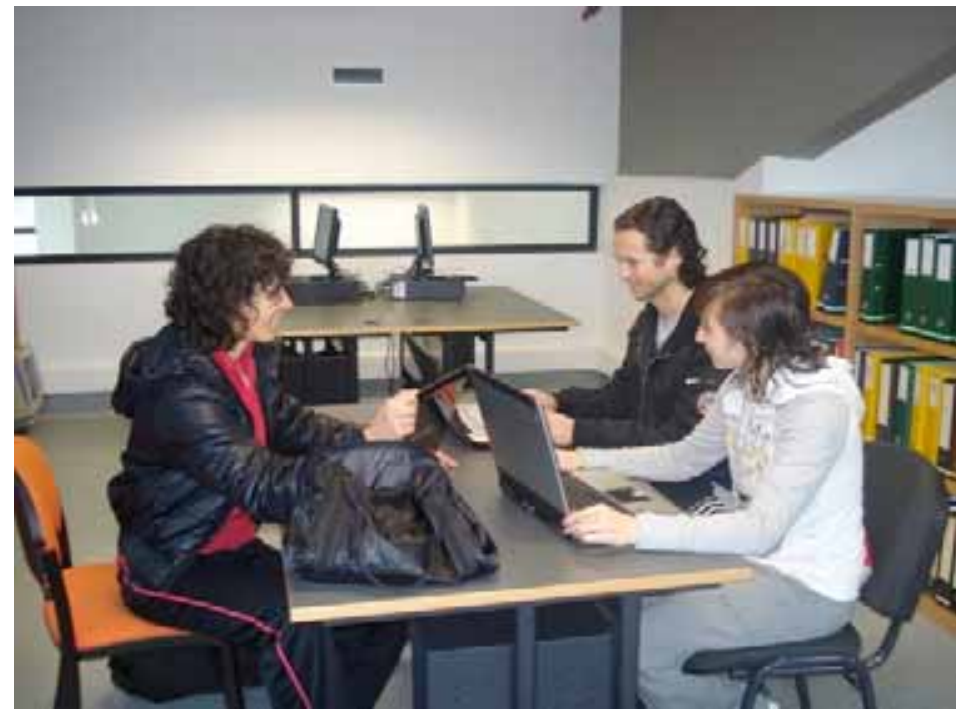

Fig. (8). Pre-service teachers meetings - Learning from each other.

significance to the relational dynamics of the School, in general, and of the PE learning area group, in particular.

Learning from a specialist in dance has been very enriching for my professional development. Not only in terms of dance skills but also with regards to my professional expectations, vision of education, interpersonal relationship development and functioning of the PE teachers, as members a professional group. [Vanessa]

On the other hand, Inês underlines the responsibility of the PE teacher in searching for a continued training and in constantly improving his or her competence. This continued training must happen beyond the academic training, teaching practice at school, and attendance of workshops. Teachers cooperate with each other by sharing their own knowledge and teaching experience. Creating, in this way, opportunities to learn from each other,

[...] is a valuable training strategy which a teacher must seek, take and give. [Inês]

In this context, Vanessa reported two more examples of collaborative relationships among teachers in which she had the opportunity to informally and spontaneously absorb new learning situations and teaching strategies from more experienced teachers:

At my lunchtime on Fridays I usually stay at the Gym with my students to supervise their PE extra trainings, such as Badminton, and preparation for the faculty's entrance athletics examinations. Meanwhile, some teachers showed up in the Gym for their first class in the afternoon and freely suggested me different teaching approaches to try on my students. So, I continue to informally learn from them. [Vanessa]

The pre-service teachers Nuno and Eduardo also highlighted the informal meetings in their speech, such as lunches and dinners with their teaching colleagues as invaluable situations for their training and intellectual construction of what being a teacher, in general, and a PE teacher, in particular, means, as expressed in Eduardo's quote below:
We can always learn something from our PE colleagues and teachers from other learning areas, in the most distinct and unexpected situations. As such, although attending lunches and dinners is not an imposed task, we almost feel obliged to attend to share, listen, absorb and learn. [Eduardo]

\subsubsection{Reflecting upon School Practice}

The three pre-service teachers selected Fig. (8), picturing them in a computer room of their school, to highlight the relevance of meeting and working together as a group to prepare their PE lessons.

Inês [left], Vanessa [front right] and Francisco [back right] met up regularly at this place to work on their lessons plans and reports. As such, this image portrays their "working moments" as a space of discussion to share knowledge, experiences and perspectives based on their written records related to the observed lessons of each other.

Inês and Francisco underline in particular the power of meeting, cooperating and going through the lessons plans of each other to enhance their planning duties and classroom performance whereas Vanessa puts the emphasis on the adjustment of her plans according to the context she is teaching in and her class needs. The following statements support these ideas:

It is very important to collect new and different opinions from my colleagues, who were in an outside position observing my PE class, about my lesson and my classroom performance, specially, on those aspects that went unnoticed to me. [Francisco]

My colleagues tell me: 'in your lesson today you did this and that but you could have done differently in order to better control your students and provide more dynamism into the class'. [Inês]

[...] So, my colleagues assume a very important role in gathering those missing parts to adjust my lessons plans and action. [Francisco]. 


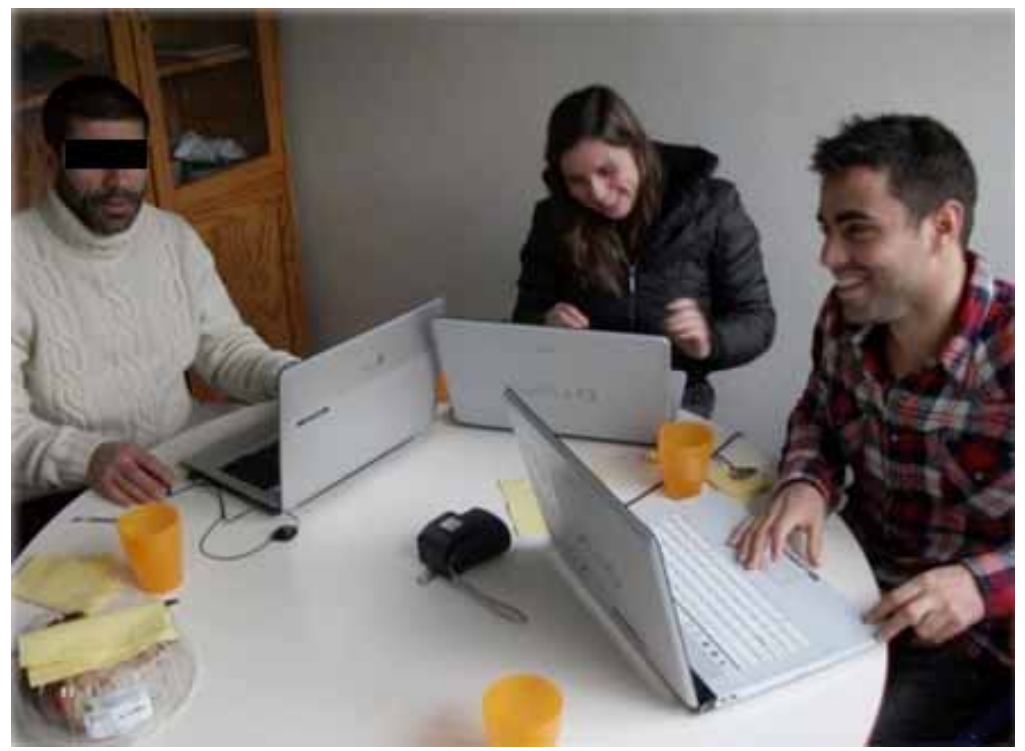

Fig. (9). Mentoring meetings - Tracking down the pre-service-teachers' professional learning and growth.

Furthermore, the pre-service teachers also pointed out another type of meeting central to their lived experiences in school as pre-service teachers and to their learning process as prospective PE teachers: the weekly meetings with their cooperating teacher.

Bárbara, Elsa and João took the photograph in (Fig. 9) in a form tutor's office where they usually meet up with their cooperating teacher on every early Wednesday mornings. The image captures the weekly collective mentoring seminars. The cooperating teacher [left] and two of his preservice teachers [centre and right] are planning and discussing their week activities while having tea and cake. Words such as discussion, sharing, reflection, learning, development and familiarity qualify the practice conducted in these pedagogical supervision meetings.

All of the pre-service teachers recognized these meetings, among themselves and their cooperating teacher, as a space invaluable to their professional development and, specially, the role of their cooperating teacher on it, as illustrated below:

These meetings are crucial to support our planning and practice class activities. [João]

Our cooperating teacher is an exceptional person and very attentive to our progressions. [Bárbara]

Moreover, good disposition and a good relationship between the cooperating teacher and the pre-service teachers, as the photograph aims to portray, are considered as fundamental to their growth as prospective teachers. Elsa's following quote accounts for this view:

This is a space of sharing, reflection and guided discovery, but also of fraternity between journey partners. We talk a lot and never about the same subject. That's why I find this reflective experience so enriching. Sometimes the cooperating teacher asks: 'How did the lessons run this week? What did you feel?'. Other times he says: 'Evaluate yourselves. In what aspects can you improve? What about the activities we're organizing...?'. In every single meeting we face a new challenge. [Elsa]

In this regard, Francisco, Vanessa and Inês also reiterate the value of the cooperating teacher in sharing knowledge and experience. This was relevant to their professional development but accentuated, in particular, the opportunity these meetings offered to collectively reflect upon their practice:

The fact that I am given the opportunity to reflect in group complements my individual reflections on my own classroom performance as a teacher. [Francisco]

In contrast, Nuno, Patrícia, and Eduardo highlighted these meetings with their cooperating teacher as crucial to learn responsibilities in addition to planning, teaching and monitoring their classes, such as the form tutor duties. Eduardo echoes the voices of his pre-service colleagues:

We've learned how to register the students' attendance rates on a specific computer software; how to assemble and to provide most of the information about children's progress to their parents, as well as any problems they might be experiencing; and how to prepare form meetings. [Eduardo]

Still regarding this topic, the participants also talked about their attendance in school meetings. Their participation in PE group meetings was invaluable to their understanding of being a teacher in school, as quoted by Francisco below:

Attending the school meetings enriched our development as teachers as whole. They enhanced our perceptions and meaning of being a teacher through the contact and familiarization with the school structure and with the main concerns and ongoing discussions happening there. For instance, in the last PE group meeting we talked about stuff like the teachers' evaluation, the value of the PE subject matter in school, the PE teaching progress through the lenses of the students' results, the establishment of strategies to improve their classifications, and the development of extracurricular activities of impact in school. [Francisco] 


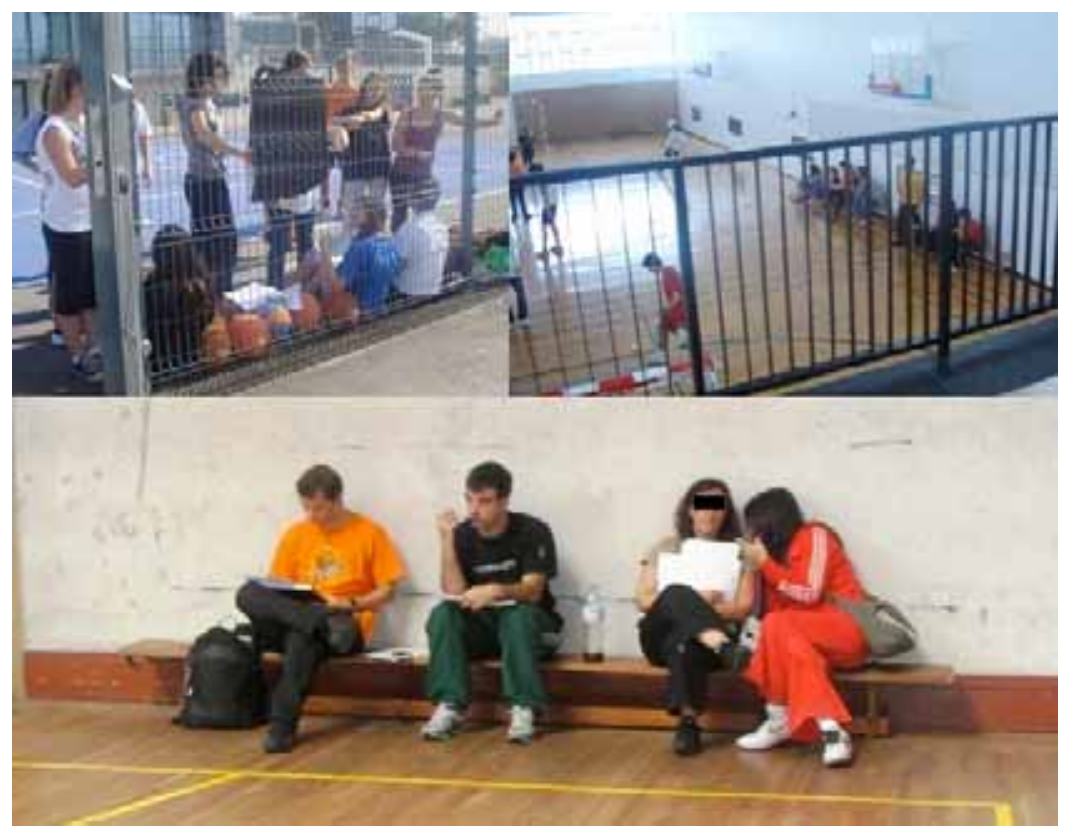

Fig. (10). Classes Observation - Learning by seeing others in action.

Finally, the pre-service teachers also transmitted the common perspective that this cooperative spirit shared in all of these types of meetings should be extended beyond the practicum stage, as Patrícia puts forward:

Cooperating with teachers; talking about our practice, not closing it up to ourselves is of paramount importance because we can learn a lot from others. [Patrícia]

Observing other teachers classes, either from pre-service teachers colleagues or from more experienced teachers, represented key moments to the participants' development as well (Fig. 10).

Particularly, observing classes run by their own peers [top-left] allowed them to detect errors in their own classroom performance of which they were not aware when teaching or reflecting upon their lessons. Francisco discloses his views while addressing to his colleague Inês PE lesson, depicted on the top-left side image in Fig. (10):

The mistakes made by our colleagues are also our own; that even after doing a retrospective analysis of our classroom performance, remain unnoticed. [Francisco].

Vanessa picks up this idea to emphasize the good features observed in a lesson rather than looking solely for performance errors.

More than perceiving what went wrong, we also learn a lot from what was done well, for example: the implementation of new ideas and strategies. [Vanessa]

Elsa agrees with this statement and adds that the dialogues and comments forged among the pre-service teachers, while observing their peers lessons, allows them to focus and reflect upon certain teaching dimensions, such as instruction and feedback, as exemplified below:

Look! Isn't it curious that we give away so many feedbacks during our lesson, either directed to the all class, to a group or event to a single student? [Elsa]
Furthermore, the participants emphasized the observation of experienced teachers' classes. The image on the top-right in (Fig. 10) depicts the implementation of class management routines in a badminton unit by an experienced teacher, captured by Francisco, Vanessa and Inês.

The pre-service teachers took the older teachers as reference and tried to take the most out of their experience.

Observing an experienced teachers' class is a compulsory task that in my opinion should occur from our own initiative since it is an invaluable piece to our training as teachers. [Francisco]

In this respect, Nuno, Patrícia and Eduardo also highlighted the classes observed by the university supervisor as a milestone to their professional development. The central image below (Fig. 10) portrays one of the supervisor's teaching rounds. The supervisor visits the pre-service teachers' schools at least three times a year to observe their lessons and assess their development. This meant all the participants were highly anxious since they know they were being evaluated. Regardless, it also represents a moment of reflection and assessment regarding their own progress as teachers in school, which is echoed in Nuno's quote below:

This is the most difficult moment to deal with in our training in school because we're being evaluated. Nonetheless, it is also one of the key components in our practicum. This is a space of dialogue, reflection and deliberation regarding the progress of each one of us. [Nuno]

The group of students is also regarded as one of the most important key elements on the participants' professional development as PE teachers.

Bárbara took Fig. (11) of herself and her students at the school Gym to emphasize that their performance, behaviours, reactions and challenges posed to her in each lesson, forces her to stop and reflect about her day-to-day 


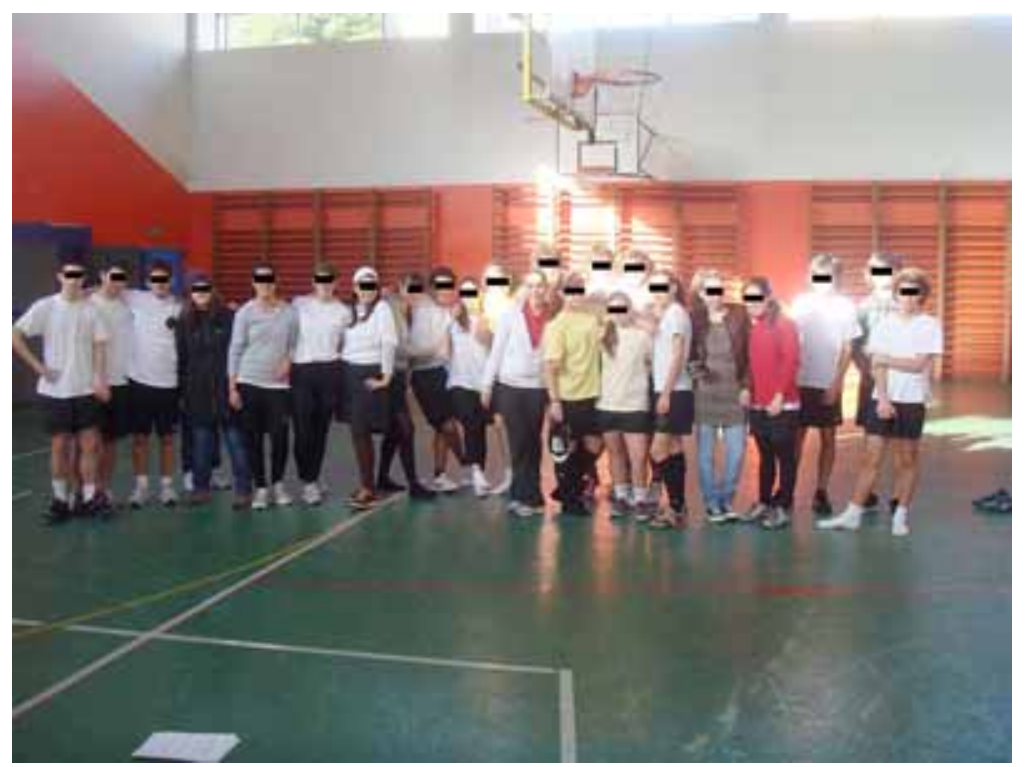

Fig. (11). The group of students - A key element to the pre-service teachers' teaching and learning process.

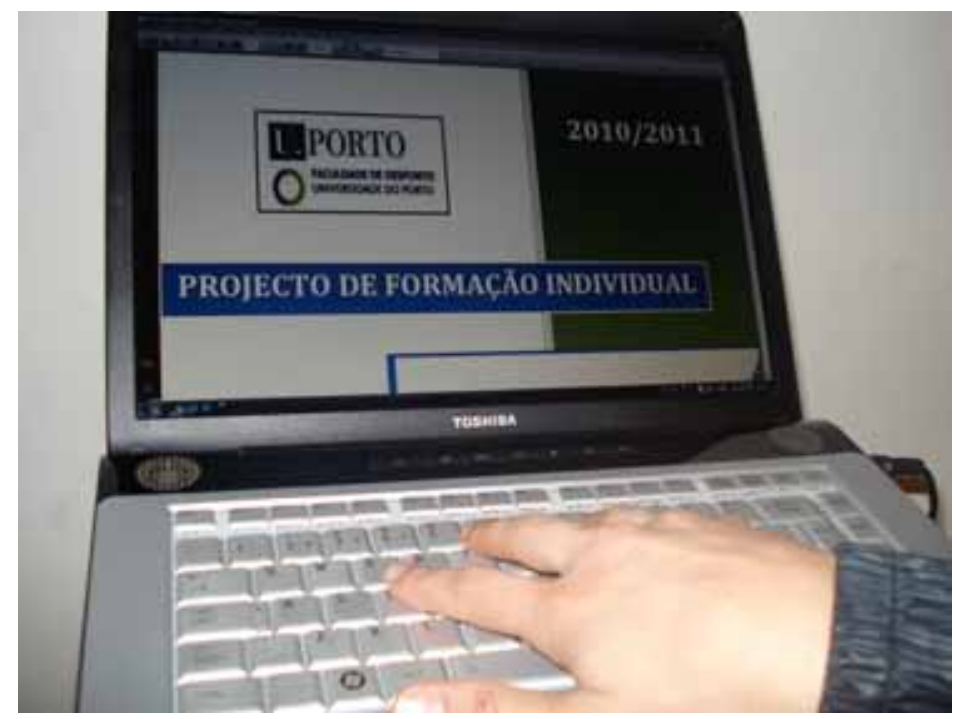

Fig. (12). Reporting work and experiences in school - Assessing their own professional development.

planning and practice, as well as on her progress as a teacher in general.

I teach my students, it's true. But they also give me much. They give much more than I thought they could ever give. It is from them, and from the challenges they put me through, that I am capable to reflect, to move forward, and emancipate myself as a teacher. [Bárbara]

Writing about their lived experiences in school also assisted the pre-service teachers on their learning and teaching process.

Fig. (12) captures a pre-service teacher's hand on the keyboard of a computer, typifying all the documentary work that he had to carry out to report his teaching practice and all school activities he participated in during the year. The Individual Training Project about his practicum experience, exemplified in the computer's screen, corresponds to one of those tasks.
Francisco, Vanessa and Inês chose to shoot and exhibit this picture to convey how much the act of systematically writing about their experiences in school [e.g. planning, teaching and evaluation, participation in school, relations established with the local community, and professional development] helped them to continually reflect about their development as teachers during their guided learning process, such as the challenges, achievements and strategies deployed to enhance their practice.

In this way, it is considered as space of self-analysis, reflection and assessment, in retrospective, about their progress as teachers in the course of the practicum year. The quote below supports this idea:

Writing about my experiences during the practicum, such as in the Final Report, gives me the opportunity to conduct a self-analysis and self-reflection on my current state of progress as a teacher. [Vanessa] 


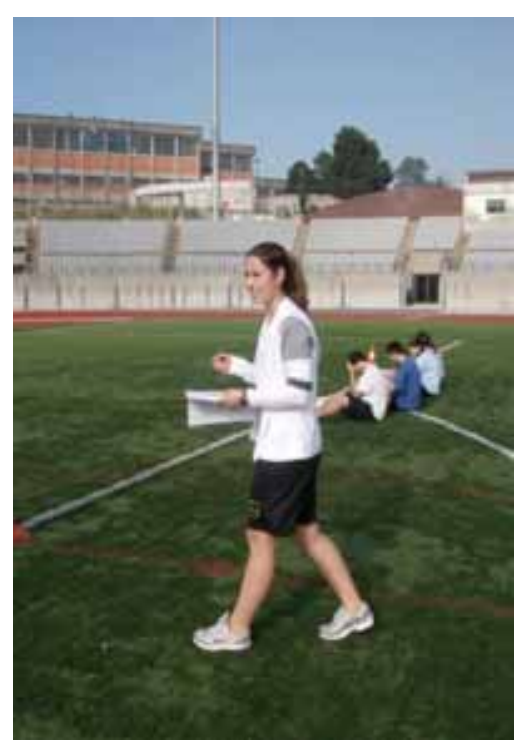

Fig. (13). Pre-service teachers' change in attitude - Drawing a smile.

With photographs (Figs. 6 and 7) and related statements, the pre-service teachers conveyed an image of the PE teacher as someone who is constantly searching for professional excellence and updating his or her knowledge.

Francisco and Vanessa's views on teacher professional learning echo those of the other participants:

I feel the need to constantly evolve and learn more in several areas. [Vanessa]

I think this is what's look like being a teacher: learning more and more on the way... [Francisco].

The sense of belonging to a group was also very present in the words of the pre-service teachers. Specifically, they searched for support amongst those with whom they shared an allegiance. They felt affinity to and had respect for particular people [e.g. the teacher expert in dancing] and identified themselves with the pedagogical strategies used in other contexts than classroom practice, such as the sport acrobatics club.

The situations depicted in the subsequent images, such as school meetings, class observations, group of students and writing-up activities were identified in the participants' discourse as invaluable elements, prescribed by their training programme, for their learning, practice and professional development as prospective PE teachers in school. The PE teacher is recognized in the participants' talk, as the type of teacher who reflects, individually or collectively, upon his or her practice, and learns and shares knowledge with their teaching colleagues.

Furthermore, these learning resources contributed greatly to the pre-service teachers' change of their stance and attitude during the practicum training as (Fig. 13) aims to portray through Bárbara's words:

Before, I was very grave and anxious. Now I am able to draw a smile while teaching. [Bárbara]
Their practical knowledge was enhanced as well, as Eduardo recounts:

Contacting with the content matter of unfamiliar sports and continuously practicing them in the field, conducted to a significant learning, not only for the students, but for me as well. These new strategies also changed the way I am and perform in class. [Eduardo]

\subsection{Social Recognition}

For the pre-service teachers, their experience in the context of the practicum training went far beyond the classroom practice duties to encompass the development of interpersonal relationships. This is particularly reflected in the cooperation with others [students, school teachers, cooperating teacher, fellow students, among others] in the school context. Meeting new people and situations related to this were deemed important in the participants' discourses for their social recognition within the school community. For instance, Vanessa and Inês exposed their views regarding both the extension of their practice as teachers, and their power to exert and being recognized for a multiplicity of roles and, thus, enhance their sociability in school.

Being a teacher is to know the content of his or her subject matter; but is also to know the school, to participate in it and socialize. [Vanessa]

Our practice goes, therefore, way beyond teaching a class. [Inês]

Several themes were, therefore, reiterated throughout their accounts to illustrate this point. The most common of which were the extracurricular activities in which they were involved: enhance their integration in school; play complementary roles to teaching; and foster a good relationship with the students.

\subsubsection{Integrating into the School Community}

The pre-service teachers, Francisco, Inês and Vanessa took the photographs illustrated in (Fig. 14), in the 'Cross Country ' race in their school, on a cold day in December. This is an extracurricular activity organized every year by the group of PE teachers. Cross-country running is one of the disciplines under the umbrella of athletics in school, typifying a long-distance track and road race on open-air courses over natural terrain.

From the photograph on the top, the pre-service teachers talked about their collaboration in the development of this school event. Namely, they were allocated to control the students' route during the competition. This role was supervised by a PE teacher [far left], older than the preservice teachers. According to them, he was a key-element to their integration in the school community. In this regard, the activity itself constituted as an invaluable opportunity to get acquainted with the school staff.

He is a very sociable person. He helped us integrating in the school. In this activity, in particular, we teamed-up with him to control the race laps, preventing the students to engage in any cheating. [Francisco] 


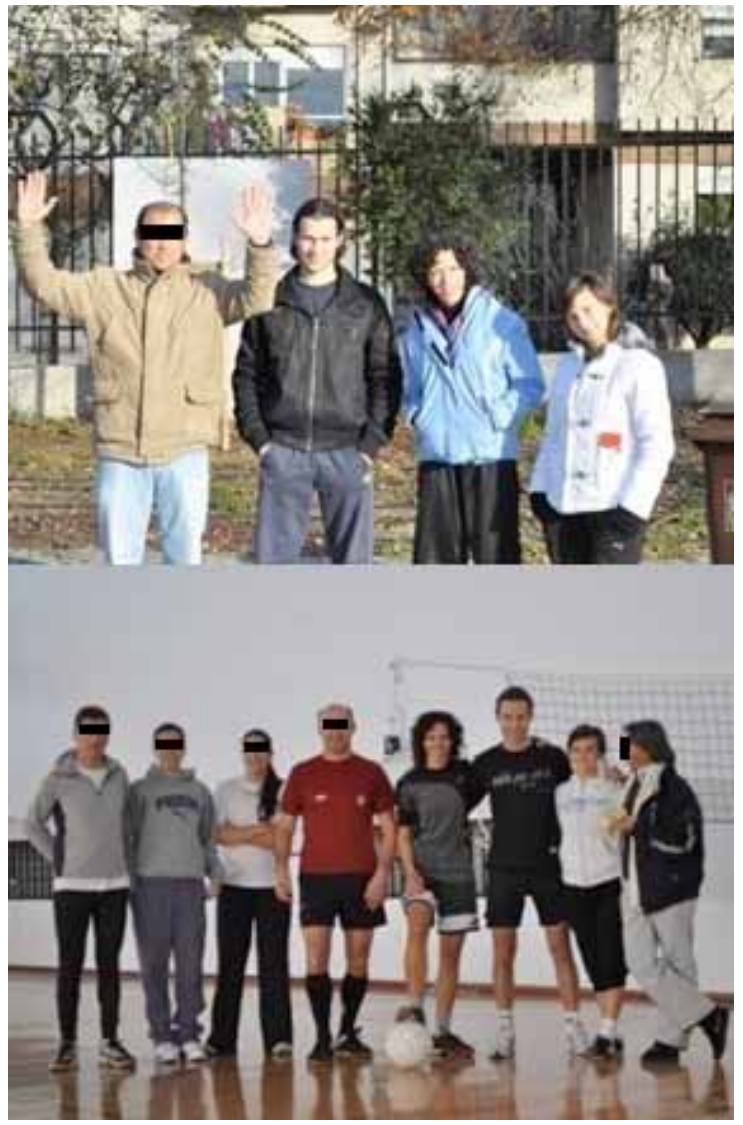

Fig. (14). School Cross-Country Competition - Promoting the preservice teachers' integration amongst the PE group.

Curiously, this integrative opportunity appeared only in December, three months afterwards the beginning of the year, as expressed in Inês quote below:

This collaboration represented our first opportunity to be involved in a PE group activity and to be integrated in the school community [Inês].

There were traits in the participants' discourses, which suggested that they expected to be accepted sooner as equal partners by the teachers in their practice school, who would trust them and involve them in their activities.

Regardless, for Francisco the photograph on the top also signified the organization of groups in this kind of activities, such as the PE group, as well as the good relationship amongst the teachers,
[...] which is something that I believe that very much characterizes us as a professional group. [Francisco]

After the cross-country competition, students and teachers teamed-up to participate on basketball and indoor football games. The photograph below (Fig. 14) depicts the pre-service teachers and their PE colleagues enjoying that moment of conviviality. For Vanessa this constituted another milestone to her integration in school due to the informal, spontaneous and festive character of the game competitions between teachers and students.

The entire organization of the Cross-Country promoted our integration, both in the PE group and in School. However, I believe that the football and basketball games played between teachers and students at the end of the race held a much significant contribution to that purpose because of their informality, fun and interactive features. [Vanessa]

Another example of an extracurricular activity, which fostered the integration of the pre-service teachers in the school where they were practicing was disclosed by João, as represented in the following photographs and related accounts.

Fig. (15) refer to a set of photographs taken by Bárbara, Elsa and João on their School's Commemorative Day held in early February. They illustrate some of the activities they engaged in during that day, namely visiting experimental work by Chemistry students [left], and doing a visual screening [right].

In particular, these photographs account for activities organized by other school's projects and learning areas than PE and School Sports, such as exhibitions of chemistry experiments developed by students and a visual screening organized by the members of the Education for Health school's project. João, as referred in the quote below, considers their involvement in the activities developed by the school community in general as one of the teachers' teaching role. Moreover, visiting the chemistry labs enhanced the opportunity for the pre-service teachers to get acquainted to other learning area teaching groups, teachers, classes and students, thus facilitating their integration in school.

We've paid a visit to the chemistry experimental lab. It allowed us to both contact with a different subject area and to relate to a different class of students. It is important that students understand that the PE teachers are interested in the work they do in other areas [...]. We, therefore, arranged our schedule so we could participate in this activity too [João].

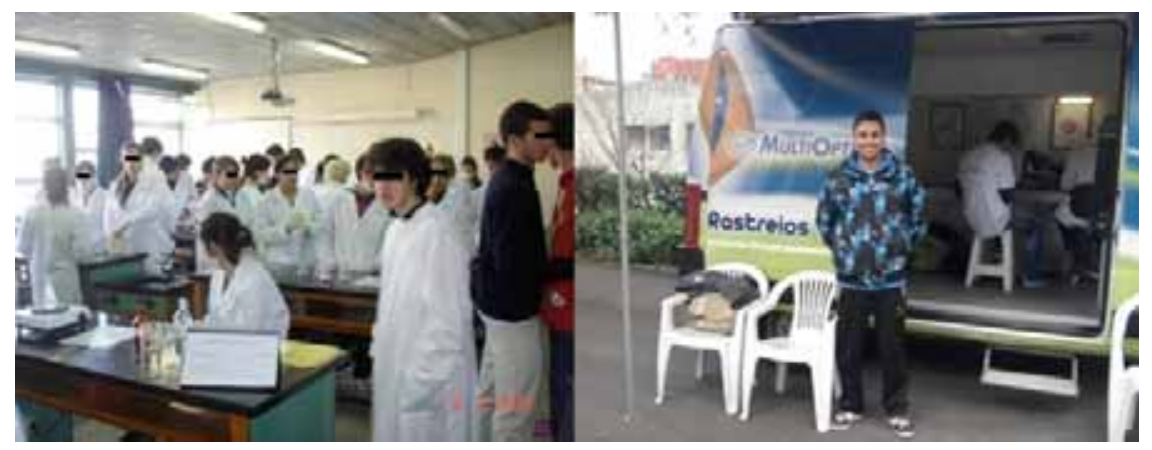

Fig. (15). Chemistry lab and Visual screening - Promoting the pre-service teachers' integration the students and other teaching groups. 


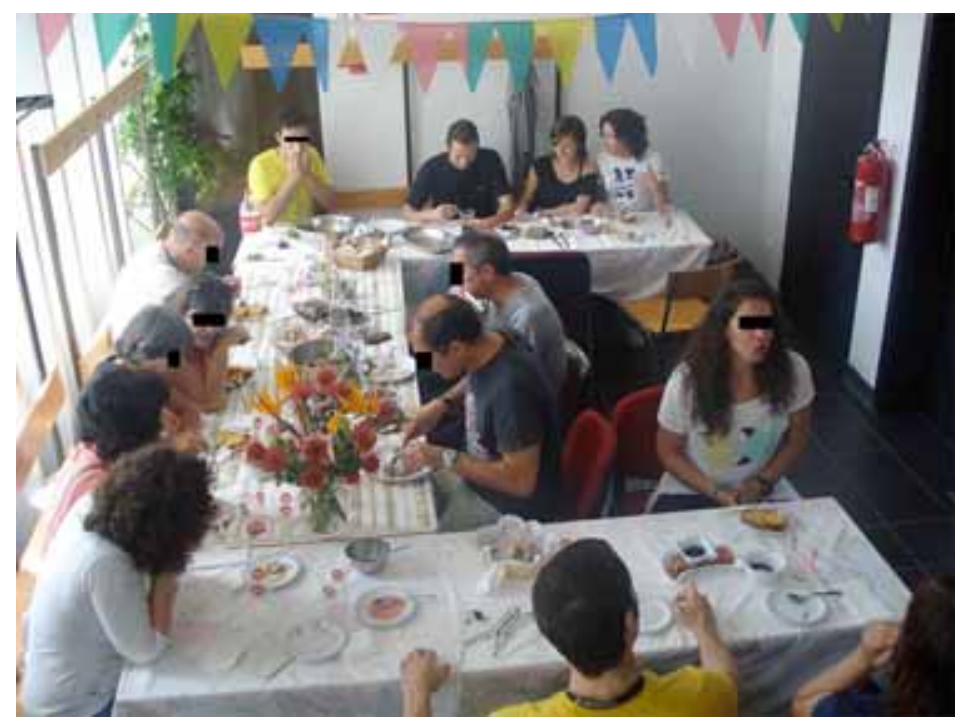

Fig. (16). PE Group Lunch - An informal interaction between pairs.

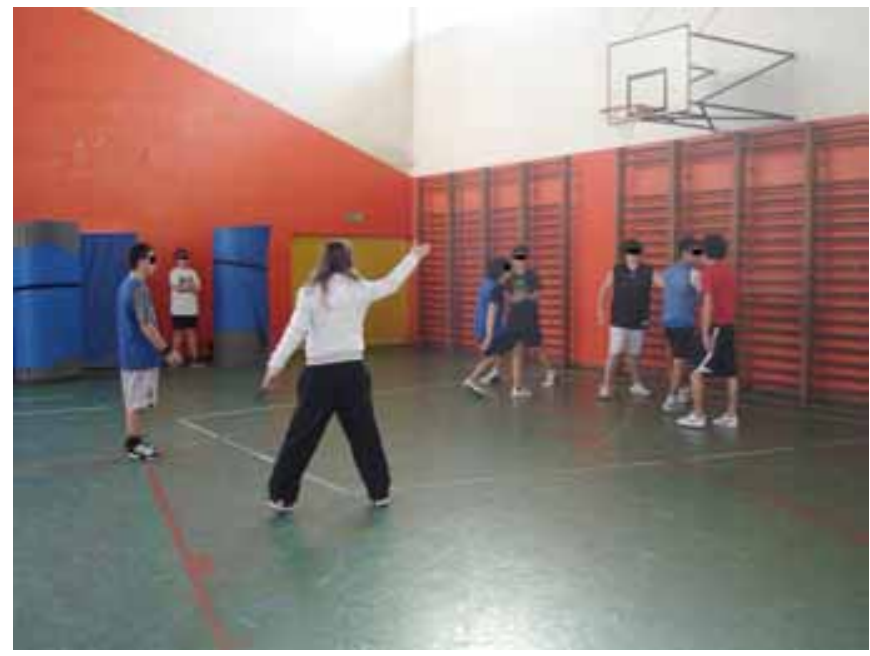

Fig. (17). Referring a Basketball game - An extra teaching role.

On the other hand, João views on the visual screening highlights the relationship between the educational topics offered by the school as an institution, in this case health, and the local community.

Similarly, Vanessa reported an activity developed by the psychology group of her school related to a conference on psychoanalysis, in which she insisted on participating. For Vanessa, this opportunity further enhanced her connection to the school community; particularly, that with her own students and other students of the school in an informal way.

The participants also talked about informal encounters such as lunches and dinners amongst teachers from their own subject matter or other learning areas, as an aspect that intensified their interaction between pairs and integration in school.

Fig. (16) depicts the pre-service teachers Francisco, Vanessa and Inês [on the far right corner of the table] having lunch with the PE group-teachers after the school-cross country activity. The PE group is made up of eleven teachers, some responsible for the $7^{\text {th }}$ to $9^{\text {th }}$ levels of education, and others for the secondary level of education.
The Fig. (16) represents the support given to them by this group of teachers, the bond established with the PE group and the school in general, as well as an additional opportunity to share ideas, experiences and beliefs with PE teachers and other professionals of education.

Indeed, the ' $U$ ' shape regarding the disposition of tables suggests a supportive and interactive atmosphere as the participants talked about. Notwithstanding, the pre-service teachers are placed together and in a corner of a table, separated from the rest of the group. This might indicate that there are differences of status and affinity between the group of PE teachers and the group of pre-service teachers in school.

\subsubsection{Playing Complementary Roles to Teaching}

Fig. (17) illustrates Bárbara refereeing a Street Basket game on the School's Commemorative Day.

This was an unexpected situation since the refereeing was originally planned to be fulfilled by students. However, a PE teacher suddenly asked her to referee the games when 


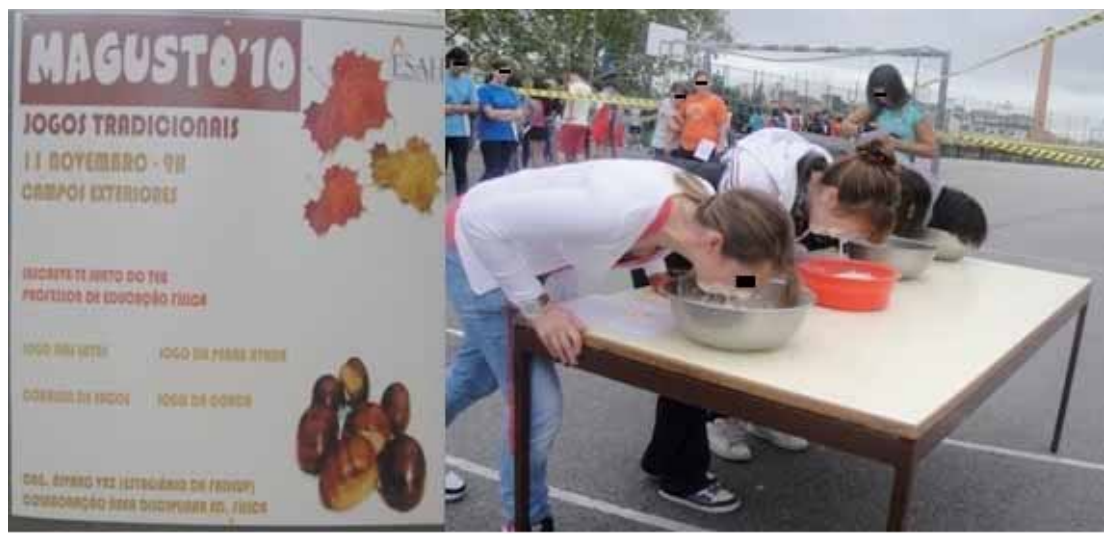

Fig. (18). "Magusto" - Developing an extracurricular activity in school.

she was entering the precinct. As such, in that particular moment and place, Bárbara had to promptly respond to the solicitation made to her and to mentally adjust and incorporate this role. Initially, she was somewhat apprehensive to perform this task.

However, the fact she had already taught basketball in her class, reviewing, therefore, its content recently, helped her carrying out this role correctly. Furthermore, the positive feedback she started receiving towards her referee duties from basketball athletes that were playing in this competition, also enhanced her determinism, satisfaction and efficacy in performing this task during the games. The haughty and rigid body posture adopted by the pre-service teacher in the photograph above, and her quote below, reveals this confidence.

Off I went! It was a very nice experience. I even refereed basketball players! In the end I was pleased to have completed this task conveniently. [Bárbara]

This photograph symbolizes, therefore, the complementary roles to teaching that the pre-service teachers carry out in school where knowledge and recognition concurred positively to the performance of this extra role. In this particular case, the transferability of practical knowledge, learned from the planning and teaching tasks, were crucial to leading these extracurricular duties. Moreover, the recognition of that knowledge and competence by others also seemed relevant to the pre-service teachers' performance in school.

The pre-service teachers, Nuno, Patrícia and Eduardo also reported a complementary task to teaching which caused some level of anxiety in them. Specifically, during their academic year in school they were expected to organize several extracurricular activities, 'Magusto' was one of those assignments. This is a Portuguese Autumn popular celebration, and to correspond to this day they planned a set of traditional games for the school community: students, teachers and staff.

The two photographs below (Fig. 18) portray the 'Magusto' festive day in their school.

Specifically, the image on the left corresponds to the programme of the day symbolizing all the planning and effort behind the organization of this activity. The photograph on the right depicts the actual day while demonstrating the students actively participating in the traditional games.

Ultimately, the images represent the pre-service teachers' ability to organize and conduct this type of assignments. However, they also represent the students' response to the calling from their pre-service PE teachers to participate in these extracurricular activities, as Eduardo exposes below:

These photographs convey their [the students] commitment and respect towards our request, as their teachers, concerning their participation in this kind of activity even though it doesn't add any extra points to their final classification in PE. [Eduardo]

Yet, the pre-service teachers' circle of action transcended the boundaries of the school.

Fig. (19) portrays the pre-service teachers Bárbara, Elsa and João, participating in the northern regional inter-school competition with the group of students qualified from their school on a sunny and cold weekend day at the "Quinta da Rabada", in Santo Tirso.

We were assigned with the role of monitoring the group of students qualified from our school to the place where the regional cross-country running was held. [Bárbara]

The cross-country running is one of the most important competitions of the school athletics activities. Every year the regional cross-country running competition takes place in three distinct regions of the country, assembling all the students who qualified in the cross-country race held, earlier, in each of their schools.

The photograph on the top-left captures the pre-service teachers [in the centre] with their group of twelve students at the entrance of the race. Specifically, João is standing up behind Bárbara and Elsa who are kneeling down, surrounded by all of the students. This collective picture symbolizes the participation of their school in this sport event.

The bottom-left image shows a male student of Bárbara finishing the race. It represents the students' physical and mental strength; their effort, perseverance, success and happiness in participating in this type of competitions. The social feature of the event and a sense of reward and gratification are also highlighted as meaningful for the students' overall education, as illustrated below: 


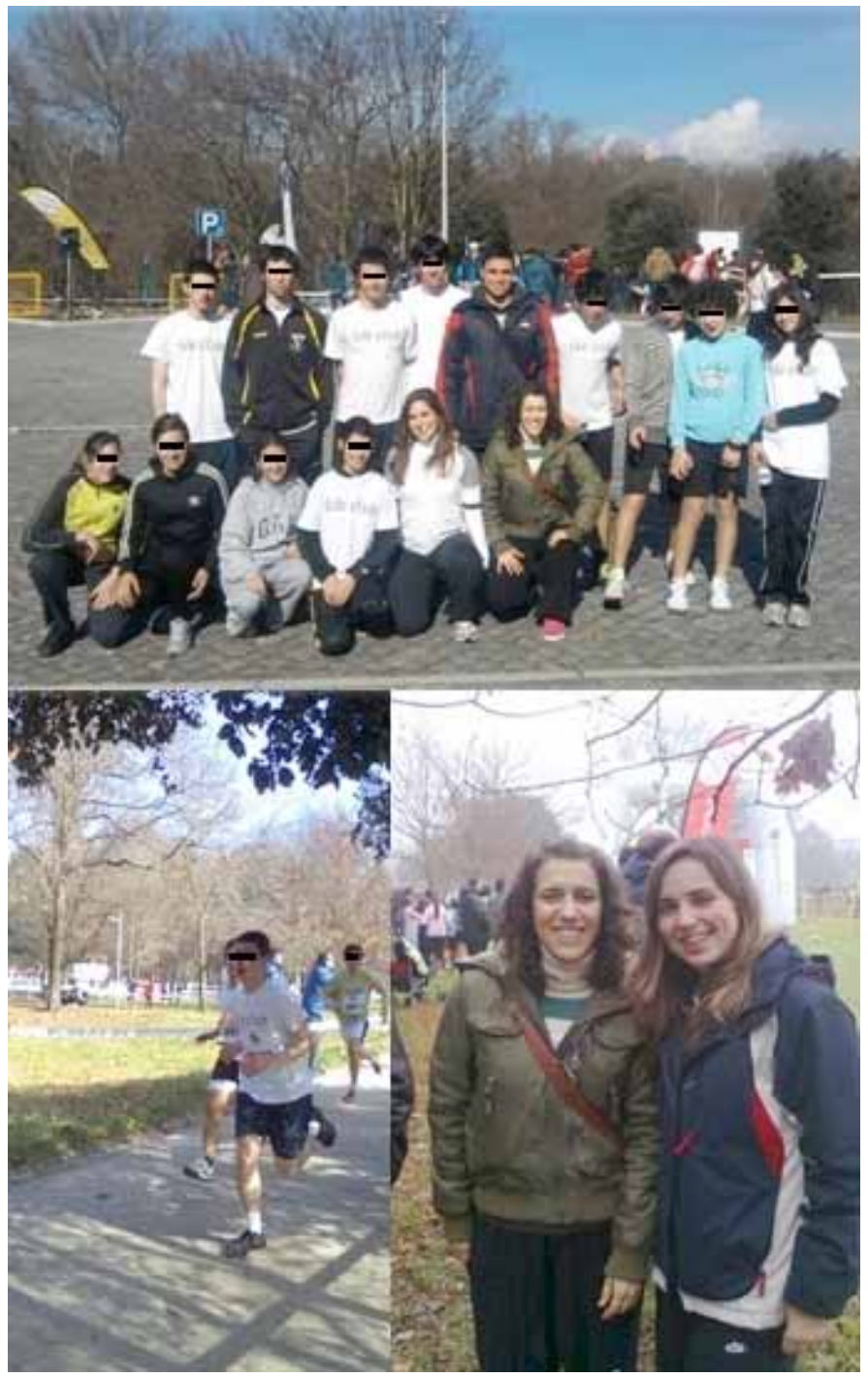

Fig. (19). The northern regional inter-school race - Representing our school in an extracurricular activity.

I'm very proud of him. He is a very shy student without an outstanding physical ability to perform such a test. However, he asked me to participate in the regional race! 'Teacher, can I go?' Fortunately, there were some dropouts and he had the opportunity to accompany us to the next phase of the race. As such, if I hadn't insisted on him to participate in the school cross-country race in the first place, he would never have had the chance to participate in this sport and social event. [Bárbara]

Finally, the photograph on the bottom-right exhibits the pre-service teachers Elsa [left] and Bárbara [right] expecting their students to cross the finish line. It represents the role of the pre-service teachers in supporting their students' participation; the good disposition of the two of them in being involved in this major competition, not as students but as teachers; as well as the festivity addressed to this type of sport events.

In this regard, Bárbara and João emphasized the richness and sociability of this sport event for all; Elsa and Bárbara highlighted the practical knowledge obtained on how these competitions are organized, as well as the fears in having the responsibility of accompanying the students in this event; and finally, Elsa and João referred to the feeling of nostalgia due to the reversal of roles played, while recalling their participation in these cross-country competitions not as teachers, but when they were students themselves.

This is an activity that I am very happy to have participated in, not only because [...] the knowledge gained about all the organization behind this event; but mostly due to the festivity and the presence of a great number of people such as teachers, students, parents and other spectators. [Bárbara]

I remember commenting with Bárbara 'Oh my god, where do we have to take the students to? What then? [...] But it was spectacular. We experienced all of those routines such as giving their snacks, taking off the athletic dorsal... that is, being in another position. [Elsa]

It was like reliving our school sport experiences when we were students. Now we experienced a whole new perspective - that of a teacher. [João] 


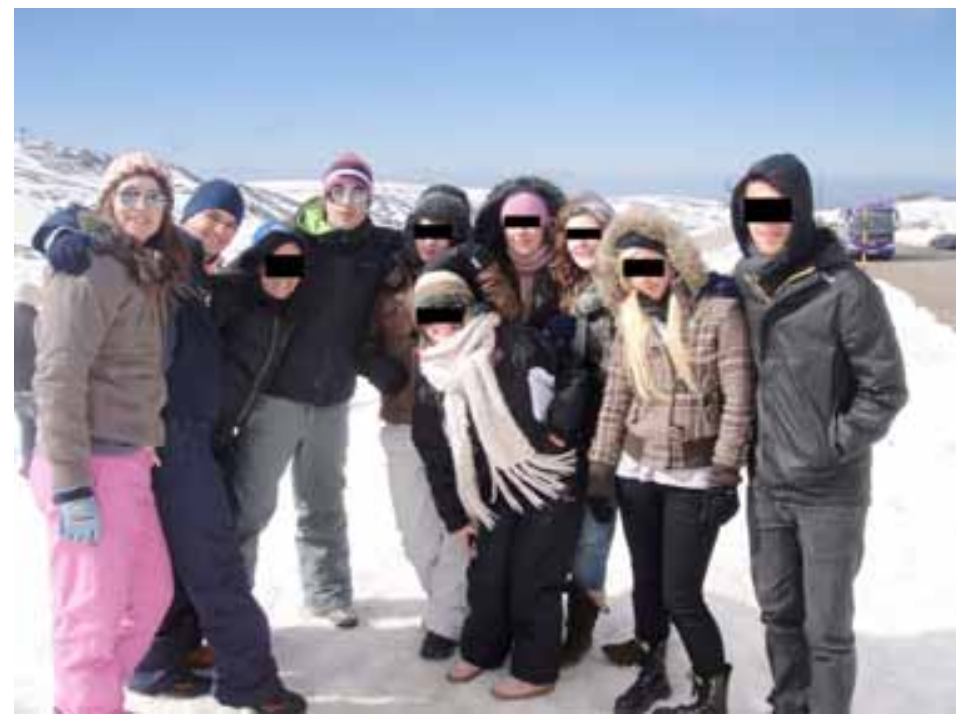

Fig. (20). School trip to "Serra da Estrela" - Enhancing a good relationship with the students.

Besides previous sport experiences as students, the preservice teachers' also revealed, in their talk, the importance of 'significant others' as, for example, former teachers, in performing their teaching roles:

We encountered colleagues from our practicum training, met old teachers of the basic and secondary school, as well as teachers from our faculty too. We relied on each other in the course of this competition. [João]

\subsubsection{Fostering a Good Relationship with Students}

In (Fig. 20) the pre-service teachers Nuno, Patrícia and Eduardo set out to organize an activity designed for the group of PE teachers and their students: a school trip to 'Serra da Estrela'. This event was planned to develop new motor skills such as skiing but mostly, as the photograph below conveys, to enhance the socializing opportunities among the pre-service teachers and their students. Each teacher was responsible by a group of students during the trip.

According to Eduardo, this visit to 'Serra da Estrela' was one of the crucial moments of his experience in school due to:

[..] the bond created between us [the pre-service teachers] and other teachers and the improvement of our relationship with our students. From this day onwards, I felt greater proximity to the class. [Eduardo]

Regardless, the extracurricular activities such as school trips, also posed challenges to the pre-service teachers both due to the responsibility of taking care of students and of dealing with unexpected situations. In this respect, Patrícia shared a singular episode with us:

We were all [students and teachers] dressing up for a nightclub party when a student got missing. So, while the other students went to the disco with a couple of teachers supervising them, we [pre-service teachers] went looking for him. Eventually he appeared at the entrance of our hotel and nothing happened. [Patrícia]
For Patrícia, this is another facet of being a teacher: being responsible for their students.

Video 1 illustrates an activity organized by a group of students framed within the 'project area' discipline held on the "School's Commemorative Day": street surfing

Bárbara is trying to sustain stand up on a board.

Bárbara talks about the informal involvement between the pre-service teachers and students provided by this activity. In this regard, she underlined the acknowledgment of her skill in doing street surfing by the students as a significant aspect in forming a new image about them, preservice teachers, on the students and in establishing a closer relationship with them.

The most relevant thing here was that students looked at me in a completely different way. There was a kid, not a student of mine, who said 'Hey teacher you can ride this? Teachers, you're very cool!' This is very informal and may not mean anything but for me it meant that I was acknowledged by the students and, that fact, was very important to me. [Bárbara]

For João this activity represented mainly the collaboration of the pre-service teachers with the students in organizing this workshop for the school's students. The boy in the right photograph is one of the students involved in the organization of this activity.

They came to us in advance to help them organizing this event and as far as it concerns me, it was a success. All credit to them. [João]

In this context, Vanessa believes that the PE teachers, and in particular, the pre-service PE teachers have a natural ability to approach students, to get close to them and, therefore, fulfill their role.

[...] maybe because of our proximity in age or our similar looks... I don't know.Either way, the truth is we can easily understand them and get into them. [Vanessa] 
Elsa evolves this idea:

The disposition of the students in a Gym is completely different from a regular classroom. We move around them, we talk, we touch, we manipulate. They like our subject. They feel motivated. So, this seems a fantastic opportunity to make a difference by conducting serious, reflective, engaging and comprehensive work. [Elsa]

Through the presented photographs and footage, the participants described several key elements and situations that illustrate their social interactions in school. All of them related to extracurricular activities. In the pre-service teachers' discourse on this theme, there are particular traits recognizing a PE teacher as someone who extends his or her school practice beyond the instruction tasks. The PE teacher is the kind of person who actively participates in the activities developed by the school community and fosters a good relationship with his or her students, teaching colleagues and school staff. The affinity domain is here very strongly represented since it is in an allegiance with others that a teacher integrates her/ himself in school, engages in complementary roles to teaching and develops a good relationship with the teaching community. Some of the participants' accounts also informed the position that a preservice teacher occupies in a school. Clearly still a student in the eyes of their teaching colleagues, and a close teacher to the students. Nonetheless, some markers of power in making their own decisions and in exercising their own actions were identified in their talk [e.g. developing their own activities and visiting the chemistry lab].

\subsection{Teacher's Mission}

The participants also accounted for a sense of mission in being a teacher, which involves assuming more elevated and comprehensive roles, such as: connecting people to sport and physical activity and the transmission of values. The situations presented below, encompass the notion of a teacher as an educator, a guide, and a model to his or her students. This concern is particularly expressed in Inês' words:

Nowadays, the children and young spend most of their time at school rather than at home with their parents. As such, the PE teacher, and the teachers in general, assume the role of sharing and passing over values to their students through their subject matter of specialization. For instance, a PE teacher can directly intercede in the hygiene and nutrition habits of the students, as well as transmit ideals of sharing and acceptance of differences of others. And, more specifically, provide extra class sport activities to both foster the sport practice in the students and to promote in them awareness for its benefits. Being a teacher is, thus, a profession of values. [Inês]

\subsubsection{Connecting People to Sport and Physical Exercise}

The following video 2 provides a glimpse to the teachers' training sessions and to the dance choreography held at school on April, $7^{\text {th }} 2011$.

The event 'Move Your Body For Your Health' is an example of an extracurricular activity created some years ago by the group of PE teachers at the school where the preservice teachers Francisco, Vanessa and Inês undertook their practicum, to motivate the students and the school community in general to actively and autonomously engage in the practice of sport and physical exercise

This promotional initiative involved all PE teachers creating a dance routine to pass on to the students of their classes to perform it together latter on to the school community. As such, two teachers, specialists in dancing designed the choreography of this academic year, and scheduled a weekly training session to teach the routine to their PE colleagues.

Francisco and Vanessa talked about the impact of this sport awareness event on students' education, the role of the $\mathrm{PE}$ teachers in it, and on their training sessions.

We met every Tuesday at lunchtime to work on the choreography. It was the only extra time we got to be together. [Vanessa]

This footage aims to emphasize the significance of the physical exercise to our health. It represents the cooperation between teachers to fulfill their mission of fighting against the sedentary behaviours installed in our contemporary society. [Francisco]

Inês also highlights the impact this type of events have on students' motivation to participate in these activities, extra to the subject matters' general curriculum, and in developing a liking for physical exercise and sport practice.

The photograph representedin (Fig. 21) was taken at the main front of a social centre for children in need by the preservices teachers Francisco, Vanessa and Inês.

Their school was contacted by this local institution requesting them to develop a sport activity with their children and young. The school principal, in turn, summoned the pre-service teachers in order to respond to the request for their assistance and a collaboration was agreed between the school and the institution.

This is a situation, which appeared this very week. It was not planned. [Francisco]

Ever since the meeting with the school principal they started planning this project together with their cooperating teacher.

We set out immediately to plan this activity. The main goal was to increase the contact opportunities of those children with a variety of sports, other than football. Particularly with those sports which they never had the chance to experience before. [Vanessa]

The pre-service teachers visited the social centre to meet the children and staff and to assess their resources. They instantly realized that they only had a football field. For this reason, most of the lessons would have to take place at their school. The activity was, then, aimed at 12 to 13 eight or nine-year old children of Year 3 and Year 4 of the primary school, and planned to happen once a week either at the social centre or at the pre-service teachers' school. The three 


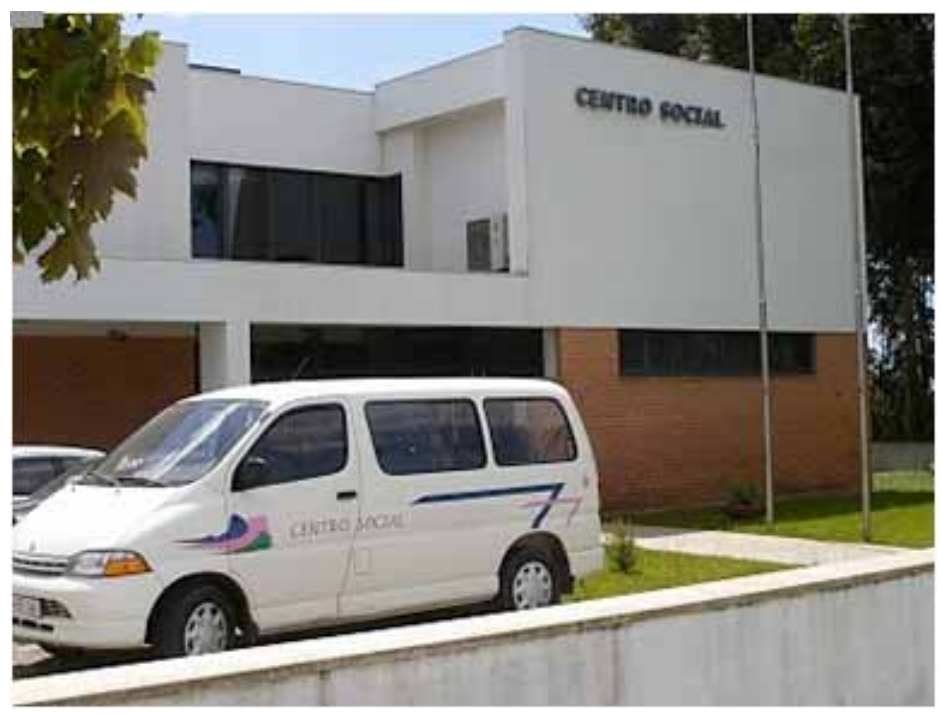

Fig. (21). Social Centre - Creating sport opportunities outside school.

pre-service teachers also all agreed to be present in the leading weeks activities to ensure the running of the first lessons. The work would thus evolve afterwards in rotation among them. Vanessa views echo the organizational conditions here exposed:

We are thinking on starting up with swimming classes since it is the sport most requested by the children. This might be explained by the fact that they only have had contact with football so far. However, this will only happen if we can count with the presence of the three of us in the initial lessons because we do not know them and we do not know whether they swim or not. So... we will minimize the risks. [Vanessa]

According to the pre-service teachers' earlier accounts, this project represents the link between the school and the local community. Specifically, the capacity of the school to respond to a request from its community. It symbolizes, therefore, them carrying over [to allude to the white van in (Fig. 21) their practice and services as PE teachers beyond the school walls, as well as an additional opportunity to work with children of distinct levels of education than those they contacted in school. However, according to Vanessa this community work also brought new challenges to them:

We had to develop new plans, new teaching strategies, and different ways to communicate with the students. [Vanessa]

Regardless of the challenges encountered, the three preservice teachers agreed upon the extra preparation provided by this initiative to enter the Portuguese teaching market in the future:

This work led to us being better prepared for our presumable future work opportunities. We establish a parallel between this work and the 'curriculum enrichment activities' developed in the elementary levels after the day core school activities, which may be our line of work tomorrow, since there are no vacancies as teachers in middle and secondary schools. [Vanessa]
In addition, Inês identifies a further meaning addressed to this task, very much related to the foundation of the Physical Education learning area both as a profession and as a pedagogical practice, which she breaks down into the three following main missions: teaching sport; raising awareness for the practice of physical exercise and sport in and out the school environment; and, more significantly, providing opportunities for all children and young to exercise and engage with sports.

We will have the opportunity to go beyond the school. That is, to grab this opportunity and raise sport practice awareness on other children while giving them a chance to learn. Because, unlike many children whose parents enrol them in various sport activities such as swimming or in any other type of extracurricular activity, there are others who never had that opportunity to experience it. So, maybe we, as Physical Education teachers, and other teachers and people from other learning areas, can contribute with our knowledge to this purpose and 'give' ourselves to them in this sense. [Inês]

In this line of thought, the pre-service teachers identified this extra role as one of the most enjoyable during their practicum training in school.

Participating in this community work was a very positive and rewarding experience both for the students and us. They enjoyed our lessons and they liked us. [Vanessa]

Fig. (22) represents a further attempt to promote the practice of physical exercise outside the school, not only by the students but also by their parents.

Specifically, the image captured by Elsa portrays two mothers, their daughters and a pair of other female students participating in the local town 'Women Race'. In the background of the picture is possible to have a glimpse to the city garden in which the race started and ended. Elsa invited the mothers of her students to participate in this event to raise awareness to the relationship between physical exercise and a healthy life and to promote a closer relationship between the students' families and the school. 


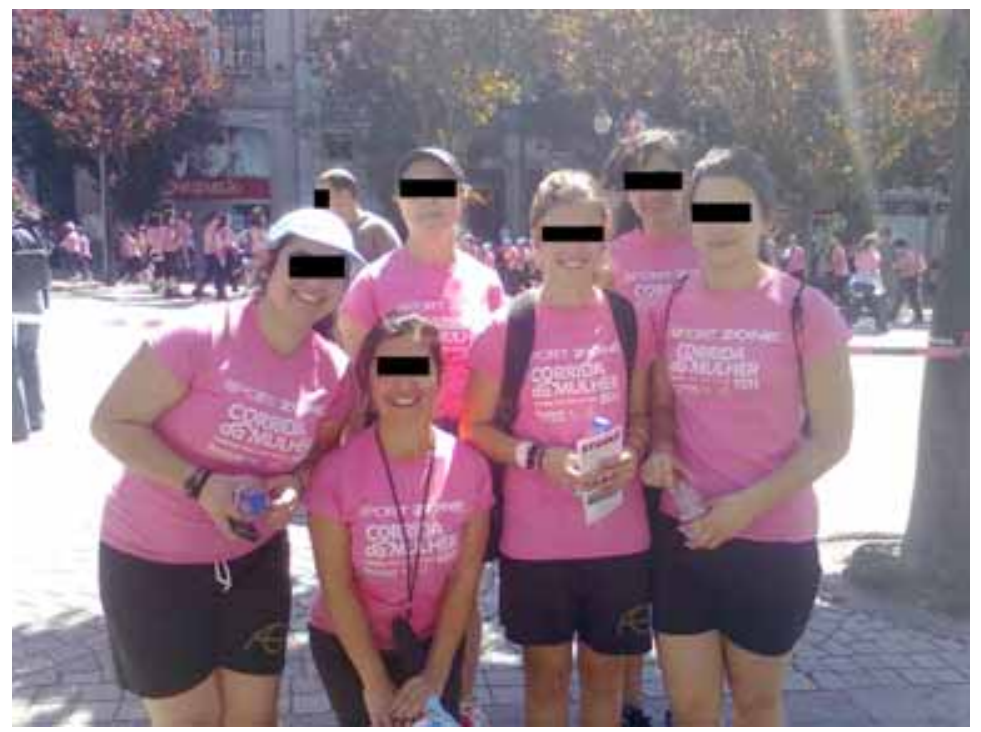

Fig. (22). Women Race in town - Promoting physical activity both in the students and their parents outside the school.

Initially, they were reluctant about participating in this race because they did not promptly grasp the interest and relevance of this initiative but, in the end, they were positively surprised and satisfied with the experience. The number of people running this race overwhelmed them. They will surely participate again next year. [Elsa]

\subsubsection{Transmission of Values}

The pre-service teachers Francisco, Vanessa and Inês created an activity to raise awareness for the person with disability and adapted sport in their school setting, termed as "The D Day" (Fig. 22).

The "D Day", the short designation for "The Disability Day', is a sport event which is developed every year by the students enrolled in the Adapted Physical Activity Master's Programme at the Faculty of Sport, University of Porto. The pre-service teachers thought meaningful to organize a similar activity in their school community to grant the higher purpose of promoting a space capable of creating feelings of acceptance in the students for the person with disability and adapted sport, as quoted below:

Our activity, 'The D Day' symbolizes the sport to all. It is an activity to raise awareness of disability and adapted sport in the secondary school setting. Its main goal is to engage and sensitize the 'normal' students towards the person with disabilities and his or hers abilities. In addition, it also aims to make them fully aware of the importance of including disabled people in our society; and to make them realize that they can also get a chance in sport, like we do. [Inês]

Fig. (23) tries, in particular, to convey the relationship between those two elements - "disability awareness" and "school", while overlaying the icon of the activity [basketball in a wheelchair] with one of the facades of the school. Moreover, and as the words - "A superação do limite", meaning "Exceeding your limits" -, printed on the window glass suggest, this activity also purported to instigate in each individual to aspire to surpass their own difficulties and barriers in order to become a better person.
In this respect, sport is a privileged arena to achieve this goal of overcoming mental and physical limitations while focusing on what one can do rather than in what one cannot do.

In order to run this event, the pre-service teachers started by looking for sponsorships [e.g. Multiópticas], contacting and inviting local institutions and associations to participate, such as CERCI [The Cooperative for Education and Rehabilitation of Non-Adapted Citizen] and the volleyball Association.

Among other initiatives, we will try to have sitting volleyball and wheelchair basketball exhibition matches in this sport event we're organizing, as well as a visual screening. [Vanessa].

We can then perceive from the pre-service teachers' later accounts that when planning the development of this sport event, they also had in mind involving the local community. Fig. (23), therefore, represents as well the pre-service teachers' endeavor to create a synergy between the school they were practicing in and its outer community.

This activity is our contribution to the school thus it also aims to establish partnerships between the school and the local community. [Vanessa]

Nonetheless, this initiative ultimately aimed to meet the general educational mission, which advocates that teachers of each disciplinary area should combine efforts in order to transmit values and attitudes of acceptance, inclusion, diversity and equality to their students.

In this last discursive theme, the participants talked about events which offered them the opportunity to go beyond what is institutionally expected (i.e. teaching and participating in school). They co-constructed the person of a PE teacher as someone who has the power to project and exercise higher roles, such as promoting the sport practice and physical activity in and out the school walls, and assisting the general education of their students through the transmission of values. For them, the PE teacher has this 


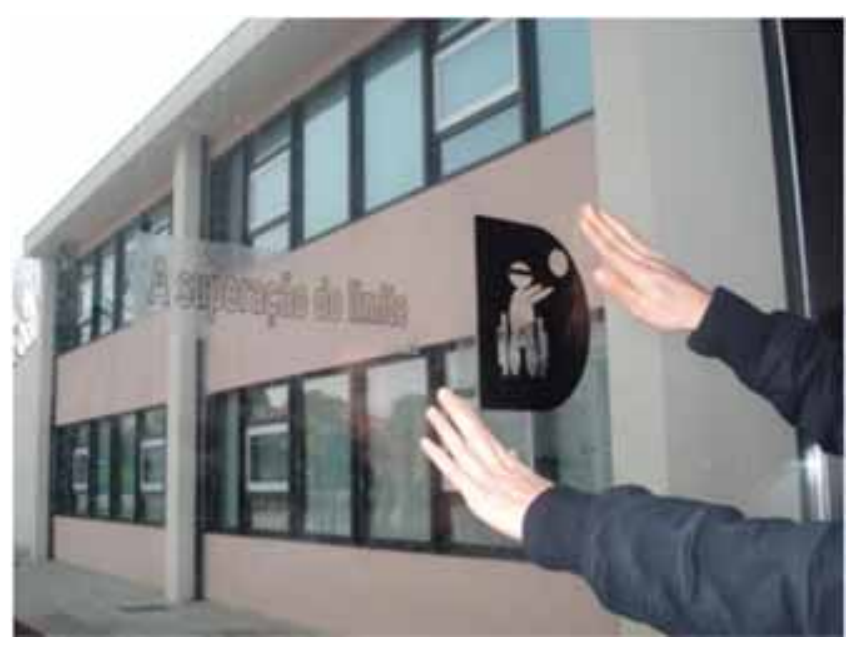

Fig. (23). The 'D-Day' - Transmitting values of acceptance and equality in school.

projective and transformative capacity. Furthermore, a collective perspective was also present in the pre-service teachers' accounts about this sense of a teacher's mission. They shared the viewpoint that this higher duty should be considered as a situation of concern to all teachers as a professional group.

\section{DISCUSSION}

To better answer the research question guiding this study: How Portuguese pre-service physical education teachers [re]construct their professional identities through talking about themselves and others in relation to their teaching practices during the practicum training?, the discussion was organized based on Clarke's cartographic analysis ${ }^{2}$ [6]. The findings of this research highlight, therefore, the various elements, situations of concern and embedded meanings in the participants' discourses, which legitimize a PE teacher identity. In addition, "photo-essays" were used to denote constructions of identity, or "ways of being "certain kinds of people'" [p. 110], [1], or, more specifically, "certain kinds of teachers" [p. 828], [20]. Though Gee defined the notion of D-Identity largely in terms of how an individual is perceived [and talked about] by others [1], for the purposes of this paper, this concept is employed to encompass the ways in which teachers talk about themselves, others and about their teacher training experience.

The results on the participants' discourses show that their own peers, the cooperating teacher and supervisor, the PE and other subjects teaching colleagues, their students and those of others, are the most valued human elements to the participants' training experience and teaching practice in school. They also underlined non-human elements, such as the lesson plan, the PE equipment, instructional and pedagogical strategies, their personal computer, school sports and the extracurricular activities as representative to

${ }^{2}$ To better address differences and complexities of postmodern social life, Adele E. Clarke offers a situational maps and analysis as an innovative supplement to traditional Glaser and Strauss's [4] grounded theory. This paper makes use of one of the maps introduced by Clarke: the situational maps. This analytic framework lay out the major human, nonhuman, discursive and other elements in the research situation of concern and provokes analyses of relations among them. The following questions that guide the outlined cartographic approach are: Who and what are in the situation? Who and what matters in the situation? What elements make a difference? [6]. them. All of these elements were related to particular events and to underlying meanings present in the pre-service teachers' discourses about their classroom practice, learning-to-teach resources, social recognition and teachers' mission.

The images depicting the pre-service teachers in classroom practice, such as studying the lesson plan, gathering the PE equipment, using different instructional models, teaching optional sport units appealing to the students, wearing attractive ornaments and using music in class, instigated the participants to talk about an institutionalized practice [1] within the teacher profession and teaching training, which is planning classroom instruction and teaching. The PE teacher is, therefore, recognized in the pre-service teachers' voices as someone who cares for planning duties and carefully prepares his or her lessons. Although the teaching tasks [in addition to classroom instruction: observing classes, writing-up reports, assisting in the form tutor duties or in the school sports practice, participating in the activities in the school and establishing synergies with the local community] included in the participants' discourses were sanctioned by the PE teacher education programme [23], the PE teacher is also described as a person who constantly searches for effective instructional strategies. Primarily, to enhance the students' learning process, and complementarily to improve their motivation and behaviour in class, as well as their commitment to the PE subject matter, and to unpopular sport units, in particular, such as Gymnastics.

In this way, the teacher is seen as a resistive and projective person [51] since he or she is constantly finding ways of surpassing the difficulties presented to them by the teaching training programme and the school structures, and of transforming the traditional perceptions of both, the teaching learning process and the teacher-student relationship [49, 50]. Regarding this, photographs illustrating the pre-service teachers implementing particular pedagogical strategies [e.g. dance steps; instructional and management routines], taken from their experiences with expert teachers and in the school sports practice to their PE classes, reflect a capacity of exercising agency [49, 50] to empower their practical knowledge and learning opportunities as teachers. 
The discursive traits of the participants regarding this issue of learning resources seemed, therefore, to represent a PE teacher as an individual who constantly searches for professional excellence and updates his or her knowledge.

The circumstances listed so far echo the outermost levels of "environment", "behaviour", and "competencies" introduced by Korthagen [21] in his 'model of levels of change' defining a good teacher. These levels are very much related to the class, the students, their knowledge and skills. Reflecting, therefore, the primary concerns of a pre-service teacher: creating a suitable learning environment, devising classroom management and student control routines, dealing with disciplinary problems, developing instructional approaches, complying with teaching assignments and, above all, enhancing their teaching abilities $[12,13,19,21$, 32].

Situations portrayed in other images, such as the school meetings, class observations, group of students and writingup activities were also identified in the participants' discourses as invaluable elements for their learning, practice and professional development as prospective PE teachers in school. They reflected both the institutionalized or legitimizing perspective $[1,23,51]$ of the teacher training programme, as pre-service teachers, and the school structure $[49,50]$, while performing the role of a PE teacher in school; as well as the reflective nature of the teaching profession [12]. For example, writing-up reports on their lived experiences in school typifies all the documentary work imposed by the practicum training and school, as well as an opportunity to carry out a self-analysis and reflection on their own progress as teachers. Similarly, the school meetings, either only among the pre-service teachers, formalized by the presence of their cooperating teacher or shared with other teachers in department gatherings or in informal encounters [e.g. lunches and dinners], appeared in the participants' talk as key moments to collect and share beliefs, knowledge and experiences, as well as to the construction of their understanding of what being a teacher in school means. In this regard, the pre-service teachers work meetings intensified their learning progress in the sense that reflecting together on each other classroom performance, contributed to the improvement of their planning and teaching skills. Likewise, the mentoring meetings offered a precious opportunity to gather knowledge and experience out of their cooperating teacher, relevant to their personal professional development. It also allowed them to collectively reflect upon their practice and learn responsibilities other than planning, teaching and monitoring the class, such as the form tutor duties. In this sense, the visits of the supervisor to observe their classes represented crucial temporal marks to their professional development. The pre-service teachers were, however, allocated into different schools and teaching structures that, somehow, conducted to distinct modes of socialization and shaped their disposition towards teaching. For instance, this was translated, in the participants' talk about the roles of certain individuals on their training: the supervisor, cooperating teacher, more experienced teachers and the school principal. The supervisor represents, on the one hand, the authority of the faculty teacher education syllabus, and the remaining elements, on the other handcon figure, "the values, attitudes and viewpoints of the [school context] floating into the [preservice teachers'] everyday [teaching performance]" [p. 682], [23]. It could be argued, therefore, that the 'institutional' perspective to which Gee [1] refers to, impacts on the pre-service teachers' identity forming, as a consequence, a legitimized identity [51].

Still regarding the pre-service teachers' discursive thematic of apprenticeship, their group of students was selected as a key element to their professional development as well, for the everyday challenges they posed, and for the reflective exercises the participants had to engage in to overcome those difficulties. Furthermore, all of the learning resources listed above contributed greatly to a positive change of the participants' attitude as teachers, during their practicum training, in terms of confidence, resolution in making their own decisions. Here, their capacity of agency is emphasised [49, 50].

Hence, the earlier discursive traits suggest a type of teacher who reflects, individually or collectively, upon his or her practice; learns and shares knowledge with their peers and teaching colleagues; and is in constant development [18, $20,22,37,38]$. These identity bids reflect both, Korthagen's intermediary levels of change - attitudes and beliefs [21]-, and Shulman's set of attributes of a pre-service teacher [12], such as their motivation to improve their practice and the capacity to engage in collective and individual reflection.

Moreover, the sense of belonging to a group was also very present in the words of the pre-service teachers when searching for "allegiance to, access to, and participation in specific practices that provided [them] the requisite experiences" [p. 105], [1]. Echoing, therefore, Gee's assertion that identities are validated in response to personal abidances [1]. That is, the participants constructed their professional identity while developing relations of affinity with the members of their professional learning community $[1,30]$. Photographs capturing the pre-service teachers with other teaching colleagues encouraged discourses which recognized them as significant elements to their learning process and social interactions in school. In particular, the pre-service teachers searched for support among those they felt commitment to [1], which included their peers, cooperating teacher, university supervisor, and other teaching colleagues. They also felt affinity to and respect for particular people and identified themselves with pedagogical strategies used by others and in other contexts than teaching. For instance, a group of pre-service teachers drew special attention to a PE teacher colleague specialist in Ballroom dancing, who taught them Cha-cha-cha steps; and another, supervising their work of controlling the race laps in the school cross-country event. Both examples convey, nonetheless, the development of a commitment to this group of teachers and that their pedagogical values and practices were influenced by "whom they identified with in school" [p. 682], [23]. However, the former situation puts in evidence the search and acquisition of practical knowledge 
by the pre-service teachers, as well as singular relational dynamics amongst teachers of a particular disciplinary group; whereas the latter, enforces the integration of the preservice teachers in the school community through their collaboration in extracurricular activities organized by the PE teachers group. The pre-service teachers also recognized the influence of significant others in helping them to deal with their own difficulties, shift from being a student to a pre-service teacher at school, and in supporting their integration in school $[32,64]$. This means that the participants also emphasized the value of good working relationships in their accounts [13, 19, 21, 32].

Regarding this, it is noticeable in the pre-service teachers' speech that their scope of action went far beyond simple instruction, to encompass also the social interactions and a more overarching role termed as the teachers' mission.

Several key elements and situations were described by the participants through photographs and footage to illustrate their social interactions in school. All of them related to extracurricular activities. These extracurricular activities, and related situations to which the pre-service teachers engaged into, either in school or in the local community, corresponded to the most significant and recurring element in the participants discourses for the multiplicity of roles they covered in their practicum training experience. Here, the duties required of a teacher go outside the teaching boundaries to recognize the significance of the extracurricular activities, as referred by Flores [32]. In the discourse of the pre-service teachers upon this theme, there are particular traits recognizing a PE teacher as someone who extends his or her school practice beyond the instructional tasks and is, for this reason, acknowledged by his or her peers. Namely, participating or developing activities beyond the core curriculum of the subject matter in school was considered as a complementary role to teaching. They also signified the acquisition of practical knowledge of how these sorts of activities are organized [e.g. school and regional Cross-country], as well as extra practice and training for the participants while preparing them to the teaching profession and current market of teaching [e.g. sport activity developed in the social centre]. These extracurricular activities also indicate the collaboration of the pre-service teachers with the PE teachers group, school and local community [e.g. school cross-country; school commemorative day] enhancing, therefore, their integration in school and their relationship with the school staff, teachers, parents and students [e.g. refereeing a basketball game, visiting the chemistry labs exhibitions and the school trip]. The affinity domain is again here very strongly represented since it is in an allegiance with others that a teacher integrates her/ himself in school, engages in complementary roles to teaching and develops a good relationship with the teaching community [1, 23]. Some of the participants' accounts also disclosed the position that a pre-service teacher occupies in a school. Clearly still a student in the eyes of their teaching colleagues, and a teacher to their students. Nonetheless, some markers of power in making their own decisions and in exercising their own actions were identified in their talk upon the images portraying them, for example, participating by self-initiative in school and community's activities $[49,50]$.
In the last discursive theme - a teachers' mission, the participants talked about events which offered them the opportunity to go further beyond what is institutionally expected, i.e. teaching and participating in school $[49,50]$. They co-constructed the person of a PE teacher as someone who has the power to project and exercise higher missions, such as promoting the sport practice and physical exercise in and out of the school walls, and assisting the general education of their students through the transmission of values. For them, the PE teacher has this projective and transformative capacity [51]. In this regard, Korthagen [21] calls for the "spirituality level" of being a teacher, also termed as "the level of mission", concerned with such highly personal questions as what is the teacher's work scope or what he or she sees as his or her personal calling in the world [p. 85]. In short, and as the author emphasises, the question of what it is deep inside us that moves us to do what we do; and of becoming aware of the meaning of one's own existence within a larger whole, and the role we see for ourselves in relation to others. This ability of extending their agency toward higher commitments in exercising their teaching roles, were also materialized, both in the selected images and their talk, in extracurricular activities. For example, the "Women's Race" symbolized the link between school, family and society; the "Move Your Body For Your Health" and the "Social Centre" events, a means to raise awareness to the practice of sport and physical exercise to all: teachers, students and their parents. The sport activity developed in the social centre offered opportunities for the sport practice outside the school setting; and the "D Day" provided an invaluable way of passing along core moral values to the students and school community in general, such as acceptance, self-worth, diversity and equality. Finally, a collective perspective [1] was also present in the pre-service teachers' accounts about this sense of a teacher's mission. They shared the viewpoint that this higher duty should be considered as a situation of concern to all teachers as a professional group. This last point, echoing similar passages in this section, highlights the fact that the discourses under scrutiny in this study were not just those used to describe specific individuals, but mostly those that apply to teachers as a group and the responsibilities of teachers as a collective $[1,23]$. It is highlighted, nevertheless, that despite the participants' understandings being jointly built and largely induced by both, the group focus and photo elicitation, the process of professional identity formation is a personal journey [65].

\section{CONCLUSION}

This paper has taken Gee's discursive perspective on identity as its core concept [1], the relationship between "structure" and "agency" [49, 50], as well as the three notions of a collective identity - "legitimizing identity", "resistance identity" and "project identity" [51], as subsidiary theories. The discourses of pre-service PE teachers about their day-to-day school practices uncovered how they [re]shaped their professional identity during their teaching-learning placement.

Specifically, the voices of pre-service PE teachers referred to their classroom practice, learning-to-teach resources, social recognition and teachers' mission. Within 
these key discursive themes, core elements, situations of concern and embedded meanings were distinguished in the participants' discourse related to their experiences in teaching practice and, consequently, to the complexity of their identity construction.

As such, the results indicate that the participants describe the PE teacher as someone who cares for planning duties and carefully prepares his or her lessons, which are examples of institutionalized roles and structure of the teaching profession. This view was particularly expressed in the preservice teachers' talk related to images depicting the preservice teachers in classroom practice, such as studying the lesson plan, gathering the PE equipment, using particular instructional and pedagogical strategies. The findings also reveal the PE teacher as a person who constantly searches for effective instructional strategies to enhance both his and her students' learning process, as well as their own practical knowledge; and, ultimately, to transform the teachinglearning process. This perspective was shared in the participants' discourse towards photographs illustrating themselves in situations which supported their learning process as teachers like: implementing pedagogical strategies transferred from their experiences with expert teachers and in the school sports practice. Other evidence points out to the same set of images disclosing a pre-service teacher capable of exercising agency while constantly searching for professional excellence and updating his or her knowledge. These identity bids built, therefore, an image of a teacher with resistive, projective and transformative abilities. The results suggest further a type of teacher who reflects, collectively and individually, upon his or her practice; learns and shares knowledge with their colleagues; is in constant development; and builds his or her identity in allegiance with others.

These identity traits are portrayed in other images, such as the school meetings, class observations, group of students and writing-up reports. The results also indicate that the participation in extracurricular activities enhanced the participants' opportunity to be socially recognized by the teaching community and to build a sense of mission. In this respect, the participants' disclosed particular features in their accounts recognizing a PE teacher as someone who extends his or her school practice beyond the instruction tasks and has the power to project and exercise higher roles. Specifically, images related, for instance, to the school cross country, refereeing a basketball game and visiting the chemistry lab described a PE teacher engaged in complementary roles to teaching, integrated in his or her school community and fostering a good relationship with other teaching colleagues, students, and the students' parents, among others. Furthermore, activities such as the "Move Your Body For Your Health", the "Women's Race", the "Social Centre Activity", and the "D Day" disclosed a PE teacher who promotes the sport practice and physical exercise in and out the school walls and assists the general education of their students. The affinity perspective is again emphasized as a feature of a PE teacher since it is in allegiance with others that a teacher establishes interpersonal relationships in school and exerts his or her mission.
We, therefore, strongly believe that the photo elicitation combined with the focus group interview technique [3, 7], i.e. the image and discourse together, unfolded new ways of exploring how the pre-service teachers learn to "become teachers" and [re]shape their teacher identities during the process. It also empowered the participants to construct a collective meaning of their teaching practices in school and, consequently, what meant for them to be a teacher, in general, and a PE teacher, in particular.

Hereby, there is a need for research to continue investing in giving voice to the student-teachers, and in using different methods, such as the visual evidence, to foreground the PE teacher education programmes and the role of identity in the process of becoming a teacher. For instance, further research should consider focusing in a single community of practice using non-participant methods of observation combined with visual records for an in-depth approach to the process of how learning about teaching occurs and how the pre-service PE teachers' construct and reconstruct their teacher identities through social participation.

\section{CONFLICT OF INTEREST}

The authors confirm that this article content has no conflict of interest.

\section{ACKNOWLEDGEMENTS}

This study was supported by National Funds through FCT - Foundation for Science and Technology [SFRH/BD/90736/2012].

\section{FCT Fundação para a Ciência e a Tecnologia

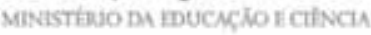

We also wish to acknowledge funding received from FEDER through the Operational Competitiveness Factors Programme - COMPETE and National Funds through FCT - Foundation for Science and Technology [PTDC/DES/115922/2009].

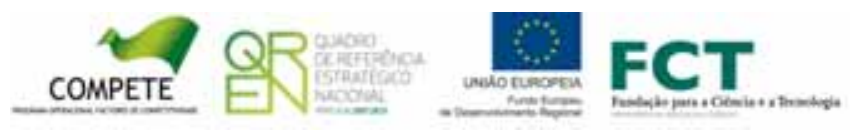

\section{SUPPLEMENTARY MATERIAL}

Supplementary material is available on the below link: http://www.benthamopen.com/tossj/articles/V007/S.M_141T OSSJ.zip

\section{REFERENCES}

[1] Gee JP. Identity as an Analytic Lens for Research in Education. Am Educ Res Assoc 2001; 25: 99-125.

[2] Clark-Ibáñez M. Framing the Social World with Photo-Elicitation Interviews. Am Behav Sci 2004; 47(12): 1507-27.

[3] Harper D. Talking about pictures: A case for photo elicitation. Vis Stud 2002; 17(1): 13-6.

[4] Glaser B, Strauss A. The Discovery of Grounded Theory: Strategies for Qualitative Research. New York: Aldine de Gruyter 1999 (1967). 
[5] Strauss A, Corbin J. Basics of Qualitative Research: Grounded Theory Procedures and Techniques. London: Sage 1990.

[6] Clarke AE. Situational Analysis: Grounded Theory Mapping After the Postmodern Turn. Symbol Interact 2003; 26(4): 553-76.

[7] Pink S. Visual methods. In: Seale C, Gobo G, Gubrium JF, Silverman D, Eds. Qualitative Research Practice. $2^{\text {nd }}$ ed. London: Sage 2010.

[8] Tannehill D. Student Teaching: A View From the Other Side. J Teach Phys Educ 1989; 8: 243-53.

[9] Sutherland L, Howard S, Markauskaite L. Professional identity creation: Examining the development of beginning preservice teachers' understanding of their work as teachers. Teach Teach Educ 2010; 26(3): 455-65.

[10] Timoštšuk I, Ugaste A. Student teachers' professional identity. Teach Teach Educ 2010; 26(8): 1563-70.

[11] Shulman LS. Theory, practice and the education of professionals. Elem Sch J 1998; 98(5): 511-26.

[12] Shulman LS, Shulman JH. How and what teachers learn: a shifting perspective. J Curr Stud 2004; 36(2): 257-71.

[13] Lamote C, Engels N. The development of student teachers' professional identity. Eur J Teach Educ 2010; 33(1): 3-18.

[14] Britzman D. Practice makes practice. USA: State of New York Press 1991.

[15] Coldron J, Smith R. Active location in teachers' construction of their professional identities. J Curr Stud 1999; 31(6): 711-26.

[16] Luehmann AL. Using blogging in support of teacher professional identity development: A case study. J Learn Sci 2008; 17(3): 287337.

[17] Akkerman SF, Meijer PC. A Dialogical Approach to Conceptualizing Teacher Identity. Teach Teach Educ 2011; 27: 308-19.

[18] Beauchamp C, Thomas L. Understanding teacher identity: an overview of issues in the literature and implications for teacher education. Camb J Educ 2009; 39(2): 175-89.

[19] Jarvis-Selinger S, Pratt DD, Collins JB. Journeys toward Becoming a Teacher: Charting the Course of Professional Development. Teach Educ Q 2010; 37(2): 69-95.

[20] Luehmann AL. Identity Development as a Lens to Science Teacher Preparation. Sci Educ 2007; 91(5): 822-39.

[21] Korthagen FAJ. In search of the essence of a good teacher: Towards a more holistic approach in teacher education. Teach Teach Educ 2004; 20(1): 77-97.

[22] Bendle MF. The crisis of 'identity' in high modernity. Br J Soc 2002; 53(1): 1-18.

[23] McDougall J. A crisis of professional identity: How primary teachers are coming to terms with changing views of literacy. Teach Teach Educ 2010; 26(3): 679-87.

[24] Watson C. Narratives of practice and the construction of identity in teaching. Teach Teach Theory Pract 2006; 12(5): 509-26.

[25] Owens TJ, Robinson DT, Smith-Lovin L. Three Faces of Identity. Annu Rev Social 2010; 36: 477-99.

[26] Helms JV. Science- and me: Subject matter and identity in secondary school science teachers. J Res Sci Teach 1998; 35(7): 811-34.

[27] Rodgers C, Scott K. The development of the personal self and professional identity in learning to teach. In: Cochran-Smith M, Feiman-Nemser S, McIntyre DJ, Demers KE, Eds. Handbook of researcg on teacher education: enduring quesions and charing contexts. New York: Routledge 2008; pp. 732-55.

[28] Holland D, Lachicotte Jr W, Skinner D, Cain C. Identity and agency in culturaal worlds. Cambridge, MA: Harvard University Press 1998.

[29] Zembylas M. Caring for teachers emotions: reflecting on teacher self development. Stud Philos Educ 2003; 22: 103-5.

[30] Lave J, Wenger E. Situated learning. Legitimate peripherical participation. New York: Cambridge University Press 1991.

[31] Lemke JL. Across the scales of time: Artifcats, activities, and meanings in ecosocial systems. Mind Cult Act 2000; 7(4): 273-90.

[32] Flores MA, Day C. Contexts which shape and reshape new teachers' identities: A multi-perspective study. Teach Teach Educ 2006; 22(2): 219-32.

[33] Enyedy N, Goldberg J, Welsh KM. Complex Dillemmas of Identity and Practice. NJ: Wiley InterScience. 2005: 68-93.
[34] Hoi Yan C. Measuring the professional identity of Hong Kong inservice teachers. J In-Serv Educ 2008; 34(3): 375-90.

[35] Connelly FM, Clandinin DJ. Shapping a professional identity: Stories of education practice. London, ON: Althouse Press 1999.

[36] Sfard A, Prusak A. Telling Identities: In Search of an Analytic Tool for Investigating Learning as a Culturally Shaped Activity. Educ Res 2005; 34(4): 14-22.

[37] Beijaard D, Meijer PC, Verloop N. Reconsidering research on teachers' professional identity. Teach Teach Educ 2004; 20(2): 10728.

[38] Kerby AP. Narrative and the self. Bloomington: Indiana University Press 1991.

[39] Cooper K, Olson MR. The multiple 'I's' of teacher identity. In: Kompf M, Bond WR, Dworet D, Boak RT, Eds. Changing research and practice: Teachers' professionalism, identities and knowledge US:Psycology Press 1996; pp. 78-89.

[40] Alsup J. Teacher identity discourses. Negotiating personal and professional spaces. Mahwah, NJ: Lawrence Erlbaum 2006.

[41] Clarke M. Language teacher identities. Co-constructing discourse and community. Clevedon: Multilingual Matters 2008.

[42] Danielewicz J. teaching selves. Identity, pedagogy, and teacher development. New York: State University of New York Press 2001.

[43] Millar Marsh M. The social fashioning of teacher identities. New York: Peter Lang 2003.

[44] Brown BA, Reveles JM, Kelly GJ. Scientific Literacy and Discursive Identity: A Theoretical Framework for Understanding Science Learning. USA: Wiley InterScience 2005; pp. 779-802.

[45] Cohen JL. Getting recognised: Teachers negotiating professional identities as learners through talk. Teach Teach Educ 2010; 26(3):473-81.

[46] Trent J. From rigid dichotomy to measured contingency. Hong Kong preservice teachers' discursive construction of identity. Teach Teach Educ 2010; 26(4): 906-13.

[47] Day C, Stobart G, Sammons P, Kington A. Variations in the work and lives of teachers: Relative and relational effectiveness. Teach Teach Theory Pract 2006; 12(2): 169-92.

[48] Phoenix C. Seeing the world of physical culture: the potential of visual methods for qualitative research in sport and exercise. Qual Res Sport Exerc Health. 2010; 2(2): 93-108.

[49] MacPhail A, Tannehill D. Helping Pre-Service and Beginning Teachers Examine and Reframe Assumptions About Themselves as Teachers and Change Agents: "Who is Going to Listen to You Anyway?". Quest 2012; 64(4): 299-312.

[50] Giddens A. The Constitution of Society. Stanford, CA: Polity 1984.

[51] Castells M. The Power of Identity. $2^{\text {nd }}$ ed. Oxford: WileyBlackwell 2010.

[52] Hagreaves A, Dawe R. Paths of professional development: contrived collegiality, collaborative culture, and the case of peer coaching. Teach Teach Educ 1990; 6(3): 227-41.

[53] Beijaard D, Verloop N, Vermunt JD. Teachers' perceptions of professional identity: an exploratory study from a personal knowledge perspective. Teach Teach Educ 2000; 16(7): 749-64.

[54] Brown BA. Discursive identity: Assimilation into the Culture of Science Classroom and Its implications for Minority Students. J Res Sci Teach 2004; 41(8): 810-34.

[55] Schempp PG, Graber KC. Teacher Socialization from a Dialectical Perspective: Pretraining through Induction. J Teach Phys Educ 1992; 11: 329-48.

[56] Fishman J. Language, ethnicity, and racism. In: Fishman J, editor. Language and ethnicity in minority sociolinguistic perspective. Philadelphia PA: Multilingual Matters, Ltd 1989; pp. 9-22.

[57] Blumer H. Society as Symbolic Interaction. In: Rose AM, editor. Human Behavior and Social Processes. London: Routledge \& Kegan Paul 1962.

[58] Mead GJ. Mind, self and society. Chicago: University of Chicago Press 1934.

[59] Bryman A. Social Research Methods. $3^{\text {rd }}$ ed. New York: Oxford University Press 2008.

[60] Leitch R. Limitations of language: Developing arts-based creative narrative in stories of teachers' identities. Teach Teach Theory Pract 2006; 12(5): 549-69.

[61] Leitch R. Masks as self-study. Challenging and sustaining teachers' personal and professional personae in early-mid career life phases. Teach Teach Theory Pract 2010; 16(3): 329-52. 
[62] Banks M. Using visual data in qualitative research. London: Sage 2007.

[63] Harrison B. Photographic visions and narrative inquiry. In: Manberg M, Andrews M, Eds. Considering counter-narratives, narrating, resisting, making sense. Philadelphia: John Benjamins 2004; pp. 113-36.
[64] Malderez A, Hobson AJ, Tracey L, Kerr K. Becoming a Student Teacher: Core Features of the Experiece. Eur J Teach Educ 2007; 30(3): 225-48.

[65] Chaix M-L. Du technicien à l'ingénieur, les transitions identitaires dans les nouvelles formations d'ingénieurs. Rech Form 2002; 41: 83-101.

Received: July 01, 2014

Revised: July 18, 2014

Accepted: July 22, 2014

(C) Cunha et al.; Licensee Bentham Open.

This is an open access article licensed under the terms of the Creative Commons Attribution Non-Commercial License (http://creativecommons.org/licenses/ by-nc/3.0/) which permits unrestricted, non-commercial use, distribution and reproduction in any medium, provided the work is properly cited. 